\title{
THE ORIENTATION OF PRIMARY TERRESTRIAL ROOTS WITH PARTICULAR REFERENCE TO THE MEDIUM IN WHICH THEY ARE GROWN
}

Richard M. Holman

\section{INTRODUCTORY AND HistoriCAL}

The orientation of plant organs relative to external agencies has long been a subject of interest, not alone to botanists but to those without botanical knowledge as well. The fact that the trunks of the trees on a steep mountain slope orient themselves without reference to substratum and grow parallel to the direction in which the attraction of gravity operates illustrates no less forcibly than does the familiar bending of the stems of house plants toward the window from which they receive light the importance of external factors in directing the plant's growth. Similar phenomena are not uncommon among animals, although, aside from our own dependence upon gravity for the orientation of our bodies, there are about us fewer examples which are obvious to the untrained observer, of the directive effect of gravity, light and other external factors upon animals. There are, however, among those animals which, like most plants, remain attached during all or a part of their existence, many cases in which the orientation of the organism is dependent upon gravity, one-sided illumination or other external agencies acting in a definite direction. Unattached and motile animals can, in many cases, be shown to have the direction of their movements definitely determined by these and other external factors. Plants offer, however, more favorable material for the study of the directive influence of these agencies which are not diffuse in their application to the organism but which operate or can be caused to operate in a constant direction. The subterranean parts of the plant as well as the structures above ground are under the influence of various agencies which affect the direction of their growth. Chief among these is gravity, and the terrestrial root furnishes a particularly favorable object for the study of the directive influence of gravity. More investigation has probably been devoted to the study of the geotropism of roots than to any other subject related to the 
irritability of any single organ of the plant. Nevertheless, a number of problems in this connection are still without satisfactory solution. The influence of the medium upon the orientation of the terrestrial root is a problem which has received only slight attention from plant physiologists and it is to this problem that the present paper is largely devoted. The investigation was prompted by the following questions:

Why do primary roots, placed horizontally or directed obliquely upward in air, exhibit, after a growth of one or two days, a very flat curvature such that the growing region forms a considerable angle with the perpendicular, whereas, in earth, roots similarly placed curve acutely and arrive at the normal perpendicular position? Why do these roots in air frequently fail to bend to the perpendicular but grow for days in a direction oblique to the direction of the stimulus of gravity, while roots in earth always return to the perpendicular when displaced therefrom?

The problem was suggested to me by Professor Wilhelm Pfeffer while I was a student in the Leipzig Botanical Institute. I wish to express my very sincere thanks to Professor Pfeffer for his constant interest and encouragement in my work while I was a student in his institute. The greater part of the work was done in Leipzig, but certain experiments were made at the botanical laboratory of the University of California. I am particularly indebted to Dr. William A. Setchell, professor of botany at the University of California, for his kindness in securing for me an excellent centrifugal apparatus. Privatdocent Johannes Buder, of the Leipzig Institute, and Dr. T. H. Goodspeed, of the Department of Botany of the University of California, also furnished advice and assistance.

As far as I have been able to determine, the first reference to the difference in behavior, relative to gravity, of roots growing in air and earth is to be found in Hofmeister's paper (1869, S. 35, ff.) in defense of his conception of the "mechanics of the penetration of the root into the soil" which had been so ably attacked by Frank. Hofmeister explained the difference in curvature of roots in air and soil as resulting from an earlier loosening of the cells of the root cap when the root was constantly wet, as he believed it to be when growing in soil, than when the root was growing in air, where, even if occasionally wetted, it was not constantly in contact with liquid water. In the latter case he supposed so little of the "plastic" root tip to be free from the encircling root cap that the root curved only very slowly while the shorter root 
cap of the roots growing in earth did not restrict the curvature of the "plastic" portion of the root to any extent. The "plasticity" of the root tip and the rigidity of the root cap, assumptions necessary to Hofmeister's explanation, are no longer tenable but, quite aside from that fact, the similarity of the curvatures executed by roots growing in water to the curvatures of roots in air is quite sufficient evidence of the incorrectness of Hofmeister's explanation.

Sachs (1874, S. 444-447) also gave some attention to this problem and one section of his paper "Ueber das Wachsthum der Hauptund Nebenwurzeln," bears the heading "Verschiedenheit der Krümmung in Luft, Wasser, Sand und Erde" and deals with the subject with which we are concerned. In another part (S. 455-456) of the same paper Sachs suggests certain reasons for this difference of behavior. He attributes the differences in the course of the curvature of roots in earth or sand on the one hand and water or moist air on the other to four factors:

I. A more rapid growth of the under than of the upper side of the curved roots in air or water. This, he believed, caused the flattening of the curvature.

2. The resistance which the earth or sand offers to change in the form of the curvature.

3. A loss by the forward part of the root of the ability to curve further.

4. The assistance supplied to the geotropic curvature of roots in earth or sand by a positive thigmotropic reaction resulting from the greater friction of the lower than of the upper side of such geotropically curving roots in their passage through the soil or sand, $i$. $e_{\text {., against }}$ the soil or sand particles.

Elfving (1880, S. 32, ff.) performed experiments in which he compared the curvature in air of inverted roots and of roots placed on a centrifuge and subjected to a stimulus of $50 \mathrm{~g}$. for 24 hours, the tips being at the beginning directed toward the axis of rotation. Observing a more complete curvature of the latter than of the former he concluded that roots in earth probably possess a greater sensibility for the stimulus of gravity than do those in air.

Nermec (I90I, $a$, S. 88-96 and 190I, $b$, S. 310-313) in two papers, devoted primarily to an effort to substantiate the statolith theory, reported experiments and observations on roots diverted from the normal position while growing in moist air. He subscribed to Sachs's 
belief that contact stimulation of roots growing in earth assists and renders more acute the downward curvature. He proposed the following two explanations for the failure of air and water grown roots to reach the vertical and for their subsequent growth straight ahead in an oblique position:

r. That through long-continued geotropic stimulation the root becomes "tired" and the autotropism of the organ gains the upper hand. This would mean that a position of rest is reached by such a root before it has curved clear to the perpendicular, except when some other stimulus such as contact assists the geotropic stimulus.

2. That during their reaction the roots undergo such a change of geotonus that they become plagiotropic like secondary roots, the perpendicular position of rest being now replaced by a new position of rest to which the root tends to return after diversion therefrom.

It is the latter of these explanations which Nermec favors. In the two papers cited and in a third (1904, S. 45-5I) appearing three years later, he reports the results of experiments in support of his theory concerning the change of orthotropic roots to a plagiotropic condition. In these papers, he also reports his observations on the changes in the supposed perceptive apparatus, changes which take place simultaneously with the taking on of the supposed plagiotropic condition.

More detail and critical consideration of these conclusions of Nermec as well as of the contributions of Sachs and Elfving will be reserved for the main body of this paper.

\section{Methods}

The seedlings employed in this investigation were grown from seeds soaked for twenty-four hours in water, rinsed thoroughly and planted in uniformly moistened sawdust which had been well rubbed between the hands and which had been placed in pots without compression. A thin layer of moist sawdust was placed over the seeds and they were then permitted to germinate at a temperature of from $18^{\circ}$ to $20^{\circ} \mathrm{C}$. In some of my experiments seedlings were grown for many days and even weeks in moist sawdust and on that account it is not out of place to comment upon the quality of the sawdust used. It was very uniform, absorbed a large amount of water and yet packed very slightly even when it had stood for many days. Roots which had grown in this medium to as great a length as $40 \mathrm{~cm}$. appeared normal in every way. 
Two methods were employed to assure a sufficient supply of water to the seedlings when the roots were kept in air during the course of an experiment. In some cases the cotyledons and the older parts of the roots were wrapped in wet filter paper or cotton while in other cases, the entire seedling, with the exception of the terminal $\mathrm{I}$ to $2 \mathrm{~cm}$. of the root, was planted in moist soil in a pot through holes in the wall of which the ends of the roots projected. At the place where they passed through the wall of the pot, the roots were wrapped in narrow strips of moist filter paper. All roots cultivated in air were frequently sprayed and the atmosphere around them was kept as nearly saturated as possible by lining the bell jars or other receptacles in which the cultures were kept with wet filter paper and in addition by maintaining as constant a temperature as possible.

When the object of an experiment required that the position of a root in air be changed after it had been under observation for some time, the seedlings were mounted on corks, each of which was cemented somewhat eccentrically in a shallow crystallizing dish. These dishes were closed with glass plates held in place by wire spring clamps and, as far as was possible without interfering with the observation of the roots, were lined with wet filter paper. The crystallizing dishes were kept on edge throughout the experiment. This was easily accomplished by fitting them into open rings of galvanized metal fastened to blocks of wood. During the intervals between observations the cultures were placed under bell jars or in zinc boxes lined with wet filter paper.

In every experiment, unless a statement to the contrary is specifically made, the seedlings were kept in darkness between observations and when they were inspected care was taken not to expose them to the light for any considerable length of time. In every experiment in which the behavior of two sets of roots under different conditions was compared, the roots of the two series were carefully matched as to length and other visible qualities before they were used; that is to say, each root in one series was of the same length and of approximately the same diameter and general appearance as the corresponding root in the other series.

Seedlings whose roots were to be under observation while growing in soil, sand, sawdust or other more or less consistent mediums were planted in Sachs's boxes or in similar boxes with parallel glass walls. When the experiment involvcd the complete inversion of a culture or 
a turning of it through $90^{\circ}$, the boxes with parallel walls were the more convenient. Boxes which were to be turned on edge or inverted during an experiment were provided with lids of paraffined heavy cardboard, perforated and held in place by wire or by means of plaster of Paris.

When, in recording the results of an experiment, it was only of importance to know the position of the terminal portion of the root relative to the vertical, the angle was measured by means of a paper protractor pasted upon a semicircular piece of zinc plate and provided with a plumb and a thread so that when the straight edge of the protractor was placed parallel with the root the thread indicated the angle of the root with the perpendicular. After a little practice the angle could be determined with an error not to exceed two degrees. When it was necessary to detect slight changes in the position of the root tip or to compare the form of the curvature of the root at intervals, a drawing camera which I have elsewhere described (Holman, 1915) was employed. This camera had the distinct advantage that, by its use, drawings could be made of the roots without changing their position relative to gravity. The drawings were made on parchment paper and those made at different times could be superimposed so that when viewed by transmitted light the whole course of the root's curvature could be followed.

Throughout this paper I have used the term "flattening" with reference to the increase in the radius of the geotropic curvature of a primary root in air which generally takes place after the geotropic curvature has reached a maximum. The word has been used in the same sense as Czapek, Simon and others have used the word "Ausgleich." It has been found convenient to employ the term "primary geotropic curvature" to designate the geotropic curvature of roots in air taking place before the beginning of the autotropic flattening as well as the geotropic curvature of any previously uncurved root regardless of the medium in which it executes the curvature. The curvature of roots subsequent to the primary geotropic curvature and to the flattening of the primary curvature has been designated in this paper as the "secondary geotropic curvature," regardless of the medium in which this secondary curvature takes place. 


\section{Cause of the Difference in Curvature of Main Roots Growing IN EARTH AND IN AIR}

As Sachs pointed out, there are two particulars in which the behavior of primary roots in air which are considerably diverted from their normal position differs from the behavior of such roots similarly placed in soil.

First, the roots in the more consistent medium do not flatten their geotropic curvature. They undergo no change in the form of their curvature after the perpendicular is reached. The roots in air on the contrary, as soon as the geotropic curvature has reached a maximum, flatten this curvature. Thus the terminal portion of the root comes to form a considerable angle with the perpendicular.

Second, the roots in air after they have undergone geotropic curvature and flattening of that curvature may elongate in an oblique direction for several days and during this time only very slight further curvature, if any, generally takes place. On the other hand, roots in soil which have executed a geotropic curvature, if again diverted from the perpendicular and directed obliquely downward, again curve into the normal position.

Now, with reference to the first of these points, there is no reason to doubt that roots which have curved downward in earth and other firm media possess the same tendency to flatten their curvature as do roots in air. That the autotropic tendency is not absent from roots growing in media which do not permit of a change of the form of the root's curvature is indicated by the results of experiments performed by Simon (I9I2, S. I37 ff.) with roots which had curved under the influence of gravity while growing in moist sawdust. When removed from this medium and kept in air these roots gradually flattened their curvature. In some cases the flattening was so extensive as to decrease by 80 degrees the angle formed by the portions of the root above and below the original curvature. This, however, demonstrates with certainty only that growth in a relatively firm medium, even for several days after the geotropic curvature has been completed, does not prevent the flattening tendency being realized after such roots are brought into the air. As I have frequently observed, however, the roots of Vicia faba and Lupinus albus may immediately flatten their curvatures to a considerable extent when, after having executed a geotropic curvature in loose sawdust, they are carefully freed from the 
surrounding medium. As a result of this immediate autotropic flattening the angle of the terminal portion of the root with the perpendicular was in my experiments sometimes increased by as much as 40 degrees. Table I shows the extent of this immediate flattening in the case of two roots taken at random from the large number observed. In this case moist sphagnum was the growth medium instead of sawdust but in the latter material the results were similar.

TABLE I

Roots of Seedlings of Vicia faba var. equina Placed Horizontally in Loose Moist Sphagnum

After 40 hours the curved portion was freed from the sphagnum.

\begin{tabular}{|c|c|c|c|c|}
\hline $\begin{array}{l}\text { Root } \\
\text { Number }\end{array}$ & Original Length & $\begin{array}{l}\text { Angle with Perpen- } \\
\text { dicular After } 40 \text { Hours }\end{array}$ & Angle After Release & $\begin{array}{l}\text { Region Involved in } \\
\text { the Flattening }\end{array}$ \\
\hline $\begin{array}{l}\text { I } \\
2\end{array}$ & $\begin{array}{l}6.2 \mathrm{~cm} . \\
7.0 \mathrm{~cm}\end{array}$ & ${ }^{1} 4^{\circ}$ & $\begin{array}{l}40^{\circ} \\
52^{\circ}\end{array}$ & $\begin{array}{l}5.8 \mathrm{~cm} . \\
3.0 \mathrm{~cm} .\end{array}$ \\
\hline
\end{tabular}

This immediate flattening or "springing" of the root after release from the relatively firm medium surrounding it is evidence that in such media the same changes in the curved region of the root take place which result in the flattening of the curvature in the case of roots in air. The resistance of soil prevents any change in the form of the root's curvature. There is nevertheless an autotropic reaction which, however, results only in a pressure being exerted by the root upon the material above it. No further explanation than the mechanical hindrance to change in the root's form is necessary, then, for the first of the two mentioned particulars in which the behavior of roots in air and in earth differ.

There is no such simple and obvious explanation for the second point of difference- $i$. e., the fact that roots in air may grow almost straight ahead in an oblique position for several days while in earth they grow straight only when in the normal perpendicular position. According to Sachs's ( 1874, S. 456) explanation, roots in air undergo a lessening of their geotropic sensibility and later Elfving also concluded that there is a lessening of the geotropic sensibility of the roots in air. Nermec (I90r, $b$ ) advanced the idea that the roots in air undergo such a change in the perceptive apparatus that they become actually plagiotropic. In addition to these two hypotheses, there is a third possibility relative to the geotonus of the root, which is that the roots in 
air become geotropically neutral after they have performed a geotropic curvature and flattened that curvature.

Quite independent of any change in the geotonus of the root, there is another factor which may be conceived of as entirely responsible for the difference in behavior of roots in air and earth or as co-operating with a weakened orthogeotropism to bring about the difference in behavior. This factor is the assistance of the root in soil or other consistent medium in the execution of its reaction by reason of some property of the medium which does not alter the sensibility of the root to the stimulus of gravity. The assisting factor might be, as Sachs suggested, a positive thigmotropic reaction in the same direction as the geotropic reaction. ' On the other hand, it might be conceived of as acting more directly, without another tropism being concerned. Thus the physical properties of the medium might be such that the root would be assisted mechanically in the execution of a prompt and complete reaction. Numerous examples can be cited where the rapidity with which a body undergoes change in direction depends upon the resistance offered by the homogeneous material through which it is moving. Thus the rudder of a boat, although able to change the direction of the boat rapidly in water would, at the same rate of speed, be unable to cause any but a very slight change of direction if the boat were moving through air instead of water. In a medium offering still more resistance than water to the passage of a body through it the same steering device would cause a more rapid change of direction than in water. Such a case may be suggested as illustrative of the possibility that the physical properties of some media may assist the root in executing a prompt and acute curvature.

I shall first consider whether a change in the geotonus of the root growing in air does actually take place, and then whether the root in earth or similar media experiences assistance or reinforcement of its curvature.

Is there a permanent change in the geotonus of roots which have grown and curved geotropically in air?

It is important to determine whether or not the change of geotonus of roots in air, if such a change does take place, is a permanent one. In order to answer this question it is only necessary to transfer roots, which have curved and flattened their curvature in air, to earth, without changing their position relative to the perpendicular. Of a great number of roots of Vicia faba var. major and $V . f$. var. equina and 
of Lupinus albus so treated, all curved downward into the vertical when placed in earth. Roots were employed varying in length from 3 to $12 \mathrm{~cm}$. Three of the longer roots did not curve downward at once into the normal position when placed in soil. They executed a more gradual curvature than the others, although they also finally reached the perpendicular. (Very frequently long roots, even when they have not been kept in air or undergone previous curvature, approach the perpendicular position only very slowly when placed obliquely downward in earth.) In spite of repeated comparisons of the rate of downward curvature of roots placed horizontally in earth directly after removal from the germinating bed with that of roots similarly placed in earth after geotropic curvature and flattening of this curvature in air, I have been unable to detect any difference in the rapidity of the downward curvature. These facts indicate that any change in the geotonus of the root which may take place in air is lost when the root is brought into earth. If, as Nermec asserts, the root growing out of the perpendicular in air becomes plagiotropic, this plagiotropism is replaced by orthogeotropism when the root is placed in soil. Also, any considerable weakening or complete loss of geotropism which the roots in air experience disappears when the roots are placed in earth or other similar firm medium favorable to growth. Whatever change in the geotonus of roots may take place in air, there is no appreciable permanent change; for upon return to soil or sand or other firm and resistant medium such roots react just as do roots which have never grown in air.

Are roots which have performed a geotropic curvature in air more weakly geotropic while they remain in that medium than are roots in earth?

As I have already remarked, Sachs and Elfving assumed a weakening of the geotropism of roots in air which resulted in the roots discontinuing their curvature before the perpendicular was reached. Sachs's assumption was not based upon any specific experimental evidence. The only basis for Elfving's ( 1880, S. 32, ff.) conclusion was the results of experiments which he performed with seedlings of Pisum sativum rotated upon a centrifuge at such a rate that the roots were subjected to a stimulus 50 times that of gravity. The experiments were continued only for twenty-four hours and at the end of that period the roots upon the centrifuge, which at the beginning of the experiment had been placed with the tips directed toward the axis 
of rotation, were found to form a smaller angle with the radius of rotation than inverted control roots, also growing in air, formed with the perpendicular. 'Since those roots which in his experiments were subjected to the more intense stimulus had taken up, after twentyfour hours, a position more nearly parallel to the direction of the stimulating force than had the control roots, Elfving concluded that it was merely on account of weakened geotropism that roots in air under the stimulus of gravity often underwent no appreciable curvature when growing obliquely downward. When subjected to a centrifugal force of 50 times the intensity of gravity the roots in Elfving's experiments must have suffered considerably from water shortage and their growth rate must have been much below that of the control roots. This fact and the short duration of his experiments make it impossible for us to know whether or not the roots grown upon the centrifuge had completed the flattening of their curvatures at the time the observations were made. If Elfving's experiments had been continued for a longer period, and if observations of the growth of the roots had been made, it might have been clear that after the same increase in length the curvatures were approximately the same.

TABLE II

Two Series of Roots of Vicia faba var. equina from 4.5 to $6 \mathrm{~cm}$. Long, of which One Series $(r)$ was Subjected to a Stimulus of $4 \times g$ to $8 \times g$ on a Centrifuge and the Other Series (c) Remained Stationary

The roots remained in moist air throughout the experiment.

\begin{tabular}{|c|c|c|c|c|c|c|}
\hline \multirow{2}{*}{ Root Number } & \multicolumn{2}{|c|}{$\begin{array}{l}\text { Original Angle of Root with } \\
\text { Radius or Perpendicular }\end{array}$} & \multicolumn{2}{|c|}{ Angle After $301 / 2$ Hours } & \multicolumn{2}{|c|}{ Growth in $30 \frac{1}{2}$ Hours } \\
\hline & $r$ & c & $r$ & $c$ & $r$ & $c$ \\
\hline $\begin{array}{l}\text { I } \\
2 \\
3 \\
4 \\
\end{array}$ & $\begin{array}{l}68^{\circ} \\
78^{\circ} \\
70^{\circ} \\
76^{\circ} \\
\end{array}$ & $\begin{array}{l}66^{\circ} \\
76^{\circ} \\
88^{\circ} \\
\cdots \\
\end{array}$ & $\begin{array}{r}14^{\circ} \\
13^{\circ} \\
9^{\circ} \\
16^{\circ} \\
\end{array}$ & $\begin{array}{l}25^{\circ} \\
70^{\circ} \\
72^{\circ} \\
\cdots \cdots \\
\end{array}$ & $\begin{array}{l}3.0 \mathrm{~cm} \text {. } \\
3.6 \mathrm{~cm} \text {. } \\
3.6 \mathrm{~cm} \text {. } \\
3.2 \mathrm{~cm} \text {. }\end{array}$ & $\begin{array}{l}2.4 \mathrm{~cm} . \\
2.7 \mathrm{~cm} . \\
3.0 \mathrm{~cm} . \\
\ldots \ldots\end{array}$ \\
\hline Mean. & $73^{\circ}$ & $77^{\circ}$ & $13^{\circ}$ & $55.6^{\circ}$ & $3.35 \mathrm{~cm}$ & $2.7 \mathrm{~cm}$ \\
\hline
\end{tabular}

On that account I performed a series of experiments to determine the actual effect of varying intensities of stimulus upon the curvature of roots in air. In some of the experiments the seedlings were rotated so that the stimulus was greater than that of gravity. In others the stimulus was less than that of gravity. Experiments were also performed in which roots in earth were subjected to a stimulus less than 
that of gravity. This was done in order to determine whether roots thus treated would, like roots in air while under the stimulus of gravity, grow straight ahead in a position oblique to the stimulating force. The centrifuge first employed was one designed for the lecture table and intended for rotation at relatively low speeds. Being without provision for self-lubrication and having a very small disc this centrifuge proved unsuitable for experiments which were to extend over a longer period than twenty-four to thirty hours at $20^{\circ} \mathrm{C}$. Experiments with this apparatus which were continued for from twenty-four to thirty hours and in which a stimulus of from 4 to $10 \mathrm{~g}$. was employed yielded, as is shown by Table II, results corresponding to those of Elfving's experiments.

\section{TABLE III}

Roots of Pisum sativum Subjected to a Stimulus of $\mathrm{I} 5 \times \mathrm{g}$ to $19 \times g$ upon the Centrifuge ( $r)$ and Kept at Rest $(c)$

Each series consisted of 5 roots.

\begin{tabular}{|c|c|c|c|c|c|c|c|c|c|c|c|c|c|c|}
\hline \multirow[t]{2}{*}{$\begin{array}{c}\text { Root } \\
\text { Number }\end{array}$} & \multicolumn{2}{|c|}{$\begin{array}{l}\text { Original } \\
\text { Length. } \\
\text { Cm. }\end{array}$} & \multicolumn{2}{|c|}{$\begin{array}{c}\text { Original } \\
\text { Angle with } \\
\text { Radius or } \\
\text { Perpen- } \\
\text { dicular }\end{array}$} & \multicolumn{2}{|c|}{$\begin{array}{c}\text { Angle after } \\
24 \text { Hours }\end{array}$} & \multicolumn{2}{|c|}{$\begin{array}{l}\text { Angle after } \\
45 \text { Hours }\end{array}$} & \multicolumn{2}{|c|}{$\begin{array}{c}\text { Angle after } \\
69 \text { Hours }\end{array}$} & \multicolumn{2}{|c|}{$\begin{array}{l}\text { Angle after } \\
93 \text { Hours }\end{array}$} & \multicolumn{2}{|c|}{$\begin{array}{l}\text { Length after } \\
93 \text { Hours, } \\
\text { Cm. }\end{array}$} \\
\hline & $r$ & $c$ & $r$ & $c$ & $r$ & $c$ & $r$ & $c$ & $r$ & $c$ & $r$ & $c$ & $r$ & $c$ \\
\hline $\begin{array}{l}\text { I } \\
2 \\
3 \\
4 \\
5\end{array}$ & $\begin{array}{l}4 \\
4 \cdot 3 \\
3 \cdot 1 \\
5 \cdot 0 \\
4 \cdot 5\end{array}$ & $\begin{array}{l}4.3 \\
4.0 \\
2.8 \\
5.0 \\
4.5\end{array}$ & $\begin{array}{l}158^{\circ} \\
143^{\circ} \\
130^{\circ} \\
130^{\circ} \\
130^{\circ}\end{array}$ & $\begin{array}{l}134^{\circ} \\
130^{\circ} \\
123^{\circ} \\
127^{\circ} \\
155^{\circ}\end{array}$ & $\begin{array}{l}65^{\circ} \\
80^{\circ} \\
77^{\circ} \\
95^{\circ} \\
76^{\circ}\end{array}$ & $\begin{array}{r}\text { I } 15^{\circ} \\
95^{\circ} \\
94^{\circ} \\
\text { I } 12^{\circ} \\
\text { I0 } 4^{\circ}\end{array}$ & $\begin{array}{l}30^{\circ} \\
50^{\circ} \\
62^{\circ} \\
65^{\circ} \\
35^{\circ}\end{array}$ & $\begin{array}{l}95^{\circ} \\
80^{\circ} \\
90^{\circ} \\
88^{\circ} \\
91^{\circ}\end{array}$ & $\begin{array}{l}20^{\circ} \\
40^{\circ} \\
25^{\circ} \\
30^{\circ} \\
24^{\circ}\end{array}$ & $\begin{array}{l}67^{\circ} \\
65^{\circ} \\
69^{\circ} \\
60^{\circ} \\
75^{\circ}\end{array}$ & $\begin{array}{l}26^{\circ} \\
16^{\circ} \\
13^{\circ} \\
20^{\circ} \\
12^{\circ}\end{array}$ & $\begin{array}{l}51^{\circ} \\
61^{\circ} \\
56^{\circ} \\
48^{\circ} \\
63^{\circ}\end{array}$ & \begin{tabular}{r|} 
I I \\
IO.I \\
8.7 \\
I 3.7 \\
I I.0
\end{tabular} & $\begin{array}{r}\text { I I.I } \\
\text { I I.7 } \\
8.3 \\
\text { I I. } \\
\text { I I.9 }\end{array}$ \\
\hline Mean. & 4.2 & 4.I & $138^{\circ}$ & $134^{\circ}$ & $79^{\circ}$ & $104^{\circ}$ & $48^{\circ}$ & $89^{\circ}$ & $28^{\circ}$ & $67^{\circ}$ & $17^{\circ}$ & $56^{\circ}$ & 10.9 & 10.9 \\
\hline
\end{tabular}

Although in these experiments, owing to the relatively low rate of rotation and the care taken to provide sufficient water, the rate of growth of the centrifuged roots was not below that of the control roots, yet the experiments were not continued for a sufficient period. On that account I performed other experiments extending over a longer period. For this purpose a centrifuge was employed having a much larger disc than the one previously used and provided with selfoiling bearings. This apparatus, which was constructed by $\mathrm{Mr}$. Arntzen, expert mechanician, civil engineering laboratory, University of California, was kept in motion by a $1 / 15$ horse power induction motor with a speed of 1,800 revolutions per minute. Speed was reduced by means of an adjustable friction drive. The revolving disk 
was made of laminated wood and upon it were mounted the zinc lined, glass covered boxes in which the seedlings were fixed. Table III gives the results of one of a number of experiments with this apparatus in which the behavior of roots of seedlings upon the centrifuge was compared with that of roots at rest. The experiment to which Table III refers was performed with Pisum sativum but similar results were obtained with Vicia faba major.

In addition to these experiments, which show clearly that increase in the intensity of the stimulus above that of gravity results in a more complete reaction of roots in air, other experiments were performed in which roots subjected to a stimulus of only a fraction of the intensity of gravity were compared with roots under the normal stimulus. The results of one such experiment are given in Table IV. The growth of the two series of roots was, in consequence of the care exercised to secure sufficient water supply, not appreciably different.

TABLE IV

Roots of Vicia faba var. equina of which One Series (r) was Subjected to a Stimulus of $\frac{1}{1} \times \mathrm{g}$ and the Other Series (c) Remained at Rest

\begin{tabular}{|c|c|c|c|c|}
\hline \multirow{2}{*}{ Root Number } & \multicolumn{2}{|c|}{$\begin{array}{l}\text { Original Angle with Radius or } \\
\text { Perpen dicular }\end{array}$} & \multicolumn{2}{|c|}{ Angle After ${ }_{44}$ Hours } \\
\hline & $r$ & $c$ & $r$ & $c$ \\
\hline $\begin{array}{l}1 \\
2 \\
3\end{array}$ & $\begin{array}{l}83^{\circ} \\
86^{\circ} \\
88^{\circ}\end{array}$ & $\begin{array}{l}87^{\circ} \\
92^{\circ} \\
94^{\circ}\end{array}$ & $\begin{array}{l}69^{\circ} \\
69^{\circ} \\
76^{\circ}\end{array}$ & $\begin{array}{l}43^{\circ} \\
34^{\circ} \\
65^{\circ}\end{array}$ \\
\hline Mean:........ & $86^{\circ}$ & $9 \mathrm{I}^{\circ}$ & $71^{\circ}$ & $47^{\circ}$ \\
\hline
\end{tabular}

As is seen in this table, decrease in the intensity of the stimulus below that of gravity results in a lesser curvature of the roots than takes place under the stimulus of gravity. As we have shown, roots under a stimulus of $n \times g$ in air tend to react as do roots in soil under a stimulus of $I \times g$. It is also important to determine whether or not roots when grown in soil and subjected to a stimulus of $g / n$ tend to execute curvatures similar to those of roots in air under the normal stimulus. With this question in mind, I experimented with seedlings of Vicia faba var. equina, planted in soil in small Sachs's boxes which were mounted upon a motor driven clinostat in such a manner that the roots were parallel to the axis of rotation. When the rate of rotation was so rapid that the stimulus exceeded $(3 \times g) /$ roo all the 
roots, during a growth of 2-4 cm., bent until the end of each coincided with a radius of rotation. The curvatures were not appreciably different from those executed by roots under the normal stimulus of gravity. When subjected to a stimulus of $(4 \times g) / \mathrm{r}$, ooo the roots, in a large proportion of cases, bent very gradually away from the axis of rotation. Then, after attaining an oblique position, they grew, in many cases, in an apparently straight line; in other cases in a curve of large radius. When similar roots were rotated at a rate only half as rapid, the stimulus being thus reduced from $(4 \times g) / \mathrm{I}, 000$ to $(\mathrm{I} \times g) / \mathbf{I}, 000$, they made no visible response. The behavior of roots planted in soil and subjected to stimuli of $(35 \times g) / \mathbf{r}, 000$ and $(4 \times g) / \mathrm{r}, 000$ is shown in Table $\mathrm{V}$.

\section{TABLE V}

Roots of Vicia faba var. equina Grown in Soil and Subjected to Stimuli of Less Intensity than Gravity

All roots originally placed parallel to the centrifuge axis.

\begin{tabular}{|c|c|c|c|c|c|c|}
\hline$\underset{\text { ber }}{\text { Root Num- }}$ & $\begin{array}{l}\text { Original } \\
\text { Number }\end{array}$ & \begin{tabular}{|} 
Angle After \\
${ }_{2}$ Cm. Growth
\end{tabular} & \begin{tabular}{|c|} 
Angle After \\
4
\end{tabular} & $\begin{array}{c}\text { Angle After } \\
6 \text { Cin. Growth }\end{array}$ & $\begin{array}{l}\text { Angle After } \\
8 \mathrm{Cm} \text {. Growth }\end{array}$ & Stimulus \\
\hline $\begin{array}{l}1 \\
2 \\
3 \\
4 \\
5 \\
6 \\
7 \\
8 \\
9\end{array}$ & $\begin{array}{l}7.0 \\
9.1 \\
7.7 \\
9.5 \\
8.7 \\
5.9 \\
6.4 \\
7.8 \\
7.5\end{array}$ & $\begin{array}{l}36 \\
46 \\
45 \\
90 \\
60 \\
53 \\
70 \\
40 \\
27\end{array}$ & $\begin{array}{r}10 \\
46 \\
30 \\
46 \\
42 \\
52 \\
67 \\
6 \\
34\end{array}$ & $\begin{array}{l}10 \\
38 \\
32 \\
36 \\
21 \\
= \\
= \\
-\end{array}$ & $\begin{array}{l}\frac{10}{32} \\
\frac{36}{二} \\
= \\
=\end{array}$ & $4 / 1000 \times g$ \\
\hline $\begin{array}{l}1 \\
2 \\
3 \\
4 \\
5 \\
6 \\
7 \\
8 \\
9\end{array}$ & $\begin{array}{r}7.0 \\
6.6 \\
7.7 \\
6.9 \\
7.6 \\
10.3 \\
8.2 \\
7.5 \\
5.9\end{array}$ & $\begin{array}{r}0 \\
0 \\
23 \\
33 \\
29 \\
0 \\
16 \\
0 \\
19\end{array}$ & $\begin{array}{l}0 \\
0 \\
0 \\
0 \\
7 \\
0 \\
0 \\
6\end{array}$ & $\begin{array}{l}\overline{-} \\
\overline{0} \\
0 \\
\overline{0} \\
0 \\
4\end{array}$ & $\begin{array}{l}\bar{z} \\
\overline{-} \\
\bar{z} \\
0 \\
0\end{array}$ & $35 / 1000 \times g$ \\
\hline
\end{tabular}

Note.-Dashes indicate that roots did not attain the length referred to.

These results show that by reducing the stimulus below that of gravity roots in earth can be caused to execute curvatures like those of roots in air under the normal stimulus of gravity.

Although all these centrifugal experiments, furnishing much more complete evidence than Elfving presented, show that changes in the 
intensity of the stimulus may exercise upon the permanent curvature of the root an effect similar to that exerted by the different media, air and earth, it by no means follows that reduced sensibility of the roots in air is the cause of the difference in behavior with which we are concerned. Some other factor may, in the case of roots in air and earth, be responsible for the differences in curvature. This factor might be the presence or absence of some agency which without affecting the sensibility of the root can assist in the execution of the reaction. Such experiments as those of Elfving, which I have extended yield no conclusive answer to the question which I have sought to answer in this section of the present paper. Elfving's conclusion is however in no way contradicted by the evidence which I have secured.

Do roots which have performed a geotropic curvature in air become plagiotropic?

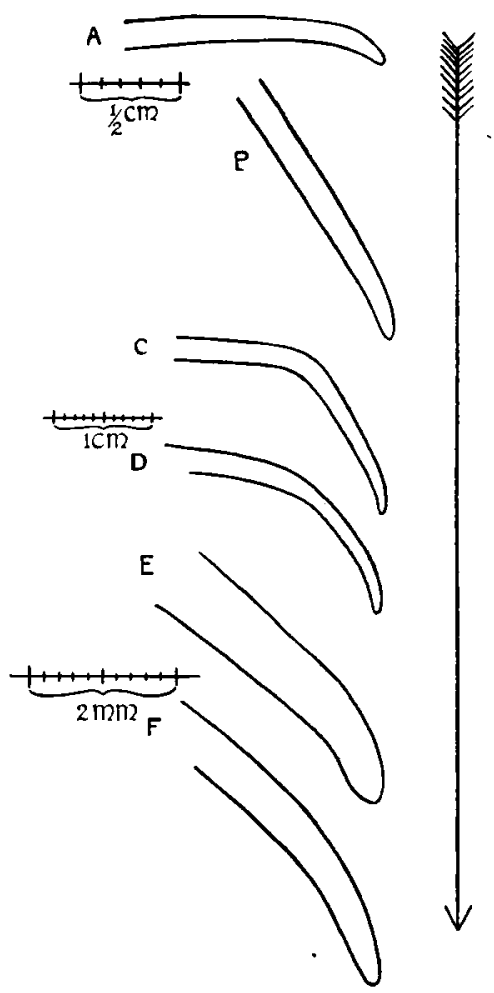

FIG. I. Primary roots growing in air and showing the tip curvature. $A$. and B.-Vicia faba var. equina; C. and D.-Lupinus albus; E.-Vicia faba var. equina (this root had grown in moist air at $15^{\circ} \mathrm{C}$. for 15 days); and F.-Vicia sativa. 
Before discussing this question it is well to call attention to the curvature, often very acute, of the terminal I to $2 \mathrm{~mm}$. of roots growing out of the normal position in air. Figure I illustrates the form of this curvature in the case of several roots used in my experiments.

This curvature of the extreme tip of the root first makes its appearance after a root has begun to flatten its primary geotropic curvature. From that time on, it persists as long as active growth continues, provided that the root is well supplied with water and that the elongating zone of the root does not lie in the perpendicular. As the root elongates the curvature is maintained at the very tip. When the cells of the curved tip pass into the phase of active elongation, the difference in the size of the cells of the upper and lower sides of the root is compensated so that the elongating zone is only slightly or not appreciably curved. In my preliminary experiments, I was struck by the constant occurrence and conspicuousness of this curvature of the extreme tip of the root. Later I found that Næmec (I90I, $a$, S. $93 \mathrm{ff}$.) had described it. It is remarkable that previous to the appearance of Nermec's paper, no one had reported this peculiar behavior of the root tip. This may, perhaps, be accounted for by the failure of earlier investigators to maintain a sufficiently high moisture content of the air in which they cultivated roots. One of Sachs's figures (I874, Fig. 1o $B$ ) shows this curvature of the tip quite unmistakably, but his paper makes no reference to it. A similar geotropic "counter curvature" of the tips of roots whose elongating zones were directed obliquely downward in consequence of a rheotropic reaction was described and figured by Berg (I899) and also mentioned by Juel (I900, S. 352) and Newcombe (1902, p. 269, ff.). The importance of this curvature of the tip in connection with the orientation of roots in different media will soon become apparent.

Now an orthogeotropic organ may be defined as one whose only position of rest is the perpendicular. Such an organ, when placed in any other position tends to curve until its sensitive zone is again in the perpendicular (cf. Jost, I908, S. 530). Similarly a plagiogeotropic organ is not merely one that undergoes no curvature when placed in a horizontal or oblique position but is an organ which tends to bend back into the original position when removed from an oblique or horizontal position. ${ }^{1}$

${ }^{1}$ Except when the organ concerned is placed with its long axis parallel to an earth radius. Czapek has shown that for secondary roots the perpendicular is a labile position of rest, regardless of whether the root tips point upward or downward. 
Nermec has put forward the hypothesis that "not too young" seedling roots of certain of the forms which $I$ have used, when inverted in moist air become, after a time, plagiotropic. The evidence upon which he based this hypothesis was threefold:

First, that in some cases roots grow for many hours straight ahead while in an oblique position or in the horizontal and that the tip, although generally forming a smaller angle with the vertical than does the elongating zone, frequently fails to reach the perpendicular.

Second, that when the tips of the roots are brought into a perpendicular position pointing downward they bend upward again into an oblique position.

Third, that when the tips of such roots are displaced from the oblique position an accumulation of protoplasm takes place in the cells of the columella, this accumulation being in the same part of the perceptive cells at which a similar aggregation of protoplasm appears in corresponding cells of secondary roots which have been displaced from their normal position.

The third reason which Nermec advanced in support of his belief that orthotropic roots may become plagiotropic cannot alone be considered conclusive. It is really significant only if the other points are definitely established.

My own numerous experiments with seedlings of Vicia faba var. major, V.f. var. equina, Vicia sativa, Lupinus albus, Pisum sativum and Ervum lens whose roots were surrounded by moist air and were placed in various positions between $30^{\circ}$ and $180^{\circ}$ from the normal position have convinced me that such roots do tend to attain a quite definite oblique position, varying from $30^{\circ}$ to $60^{\circ}$ from the perpendicular. Thereafter active curvature takes place very slowly if at all. The position of the terminal portion of the root may however change owing to passive bending of the region behind the zone of elongation by reason of the increasing length and weight of the younger part of the root. Roots of Vicia faba and Lupinus albus up to 2.5 or $3 \mathrm{~cm}$. in length when placed horizontal in air generally bring the elongating region into this oblique position within 24 to 36 hours at a temperature of $18^{\circ}$ to $20^{\circ}$. Older roots require a longer time. This oblique position in which the root frequently elongates without further active curvature is generally attained by an extensive geotropic curvature and subsequent autotropic flattening of the geotropic curvature. Often in the case of roots which are of considerable length before being 
employed for the experiment there is no rapid and extensive downward curvature which is later flattened. Instead the root curves gradually downward until a position is reached varying from $60^{\circ}$ to $30^{\circ}$ from the perpendicular. When the seedlings are so mounted at the beginning of an experiment that the roots are directed obliquely downward, the geotropic curvature is slight and in the great majority of cases completely flattened. The root, straight throughout except for the curvature of the extreme tip, then generally elongates without further appreciable active curvature. When roots after being taken from the germinating bed are directed obliquely upward a longer time is required for the attainment of the position in which they point obliquely downward than when the roots are placed horizontal. Old roots, especially those of Vicia faba and Lupinus albus when placed at an angle of $45^{\circ}$ above the horizontal often fail to curve below the horizontal before growth comes to a standstill ${ }^{2}$ and inverted roots of these species if longer than $3 \mathrm{~cm}$. at the beginning of the experiment often fail even to reach the horizontal. This corresponds to the observations of Němec (I90I, $a, \mathrm{~S} .94 \mathrm{ff}$. and I90I, $b, \mathrm{~S} .310$ ) but his statements on the subject refer to roots which were under observation only for a period of from thirty-six to forty-eight hours after inversion. In many cases, though, roots which after two days are still directed ubliquely upward or horizontally later bend gradually downward until they point obliquely down. There are frequently, however, cases in which inverted roots do not reach the horizontal even after as long a period as ninety-six hours. Roots of relatively large diameter such as those of Vicia faba and Lupinus albus in contrast to the slenderer roots of Pisum sativum, Ervum lens, Vicia sativa and Phaseolus nanus most frequently behave in this manner. In the case of roots placed in air at an angle more than $45^{\circ}$ or $50^{\circ}$ above the hori-

${ }^{2}$ Sachs ( 1874, S. 409 ) reported that roots of Vicia faba, after 3 to 4 days in air ceased growing entirely. By exercising all possible care, I have succeded in maintaining a relatively active growth for 12 to 13 days after the roots were brought into moist air. For example, of ten roots ranging in length from 2 to 13 centimeters placed horizontal in moist air and subject to a temperature of $17^{\circ}$ to $18^{\circ}$, the following are the mean elongations for successive periods: Ist day-2.04 cm., $2 \mathrm{~d}$ day$1.99 \mathrm{~cm} .3^{\text {d day }}-1.35 \mathrm{~cm} ., 4^{\text {th }}$ and 5 th days (forty-two hours)-2.14 cm., 6th and 7 th days (forty-eight hours) $-2.24 \mathrm{~cm}$., 8 th and 9 th days (fifty-three hours)-I.26 $\mathrm{cm}$., Ioth and I Ith days (forty-eight hours) $-.86 \mathrm{~cm}$. One of the ten roots did not grow during the roth and $\mathrm{I}$ Ith day and seven others did not grow after the IIth day. Two of the ten roots, however, grew during the I2th and I3th day, respectively 1.4 and $.8 \mathrm{~cm}$. durıng the forty-eight-hour period. 
zontal there is a slow downward curvature subsequent to the primary geotropic curvature and the flattening of that curvature. This secondary geotropic curvature, which may continue for as long as four to five days, appears to be due to a slight residue of the curvature of the extreme tip which is retained by the cells as they pass over into the phase of elongation. During this secondary geotropic curvature,

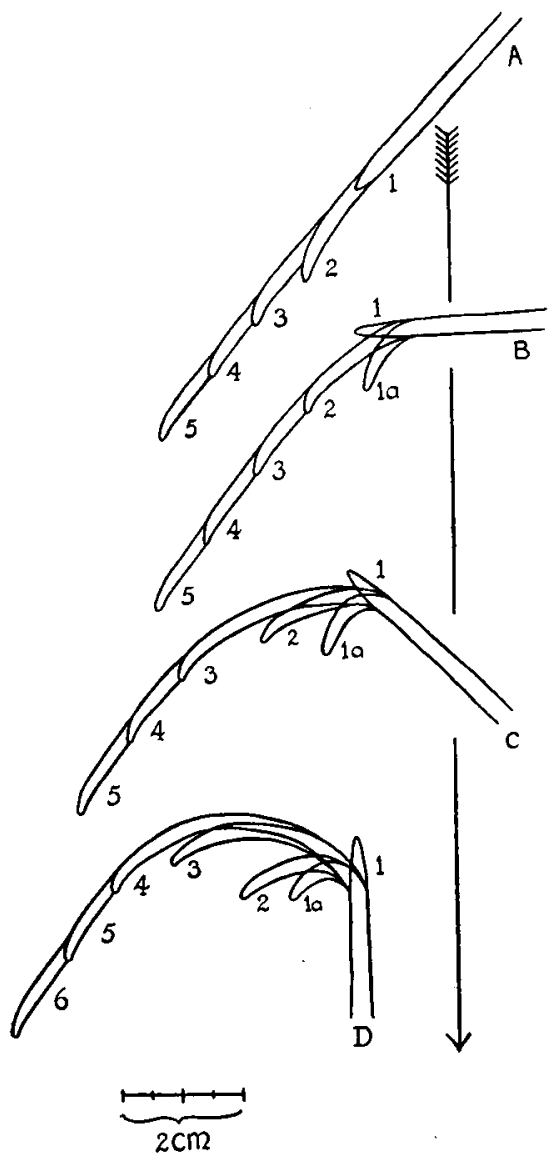

FIG. 2. Diagrams showing the behavior of roots of Vicia faba var. equina about $2 \mathrm{~cm}$. long when placed in air at the angles shown at $I$ in the diagrams.

the residue of the primary geotropic curvature of the root frequently undergoes further flattening. As a result of this decrease in the 
curvature of parts of the root which have discontinued growth (cf. Simon, I912, S. I33 ff.) the residue of the primary curvature may become so flat as to be indistinguishable from the very gradual secondary curvature. The failure of roots of Vicia faba and Lupinus albus which are longer than 4 or $5 \mathrm{~cm}$. when inverted to bend below the horizontal is probably due to a slackening of the geotropic sensibility with length. Roots of large diameter when executing a curvature must maintain a greater difference in the size of the cells of the upper and lower sides than would slenderer roots. It is not unlikely that on that account a relatively greater intensity of geotropic stimulus is necessary to bring about corresponding reactions.

The behavior, described above, of roots variously placed in moist air is illustrated by the diagrams shown in figure 2. These diagrams were based upon a large series of camera drawings of roots of Vicia $f a b a$ var. equina which were approximately $2 \mathrm{~cm}$. long when displaced from the normal perpendicular position. Roots of Lupinus albus behaved in substantially the same manner.

Observation of roots of these species and of Pisum sativum and of other leguminous species indicates that, as illustrated in figure 2 , roots in air when displaced from the normal position by more than $40^{\circ}$ to $50^{\circ}$ tend to take up a position in which the elongating region is directed obliquely downward, after which active curvature almost or entirely ceases. This fact does not however constitute conclusive evidence of the root having become plagiotropic. The failure of the root to undergo active curvature after this oblique position is reached can as well be explained by assuming that, after the primary curvature and its flattening have taken place, the relation between the autotropic and the geotropic impulse is altered in favor of the former and that a position of rest is then attained only after the inclination to the perpendicular is reached at which autotropism and geotropism are in equilibrium.

The crucial test for plagiotropism in the case of the roots in air is that which Nermec (cf. p. 290 of this paper) states that he applied with positive results. I performed a number of experiments to determine whether the supposedly plagiotropic roots would actually bend upward into an oblique position when directed perpendicularly downward. Roots which had grown for one or two days in an oblique direction in air (as shown at 4 and 5 in figure 2) were placed with the tip pointing directly downward, the roots remaining in moist air. 
The results of these experiments, in which the behavior of the roots was followed closely by means of enlarged tracings made with a camera, were entirely uniform. I found no case in which the root showed any tendency to bend upward and grow in an oblique direction. An account of one of the numerous experiments performed in this connection will be given here. Three seedlings of Vicia faba var. equina, whose roots were 2 to $2.3 \mathrm{~cm}$. in length, were so placed that the roots were directed obliquely downward in moist air at an angle of $50^{\circ}$ from the vertical. After sixty-four hours these roots were straight except for the curvature of the extreme tip and they were then so placed that the tips pointed directly downward. During the following seventy-seven hours, in spite of active growth, most careful observations made by means of enlarged camera drawings failed to show any trace of an upward curvature. No other change in the roots was noticeable except the increase in length and loss of the slight curvature of the root tips. Roots which were originally placed horizontally in air and which had reached the oblique position behaved in the same manner when they were turned until the tip pointed directly downward. Experiments with Lupinus albus yielded the same results as those with Vicia faba var. equina. Similar results were also obtained with roots which, after growth in the oblique position in air, were transferred to other media. Thus, of five roots of Vicia faba from 3.5 to $5.5 \mathrm{~cm}$. long, placed at angles of from $30^{\circ}$ to $50^{\circ}$ in air, all, after having elongated from 4 to $5 \mathrm{~cm}$. in the oblique position, grew straight ahead when the tips were directed downward and the roots surrounded by earth (in 2 cases) or loose moist sawdust (in 3 cases). Similar results were obtained with five roots of the same species which were similarly treated except that they were placed horizontal in air at the beginning of the experiment. After forty-eight hours they had reached an oblique position from $30^{\circ}$ to $50^{\circ}$ from the vertical and had elongated in that direction for some time, but when the tips of these roots were directed downward no upward curvature of the root took place. These results not only indicate that these roots had not become plagiotropic but also that they did not possess any induced dorsiventrality such as not infrequently occurs in the case of rhizomes and of branches of subaerial stems.

However in certain of Nermec's (I90I, $a$, S. 9I, 92) experiments he obtained results which certainly seem to indicate an assumption of plagiotropism by the roots with which he experimented. He 
placed roots which were not "too young" in air with tips directed ver tically upward. Then, after they had curved until the elongating region was approximately horizontal and the extreme tip acutely curved so that it pointed obliquely downward, he displaced the seedlings so that the tips of the roots were directed straight downward. At this time the roots were surrounded by moist sawdust. He subsequently observed an upward curvature of these roots opposite to the curvature of the tip at the time the roots were placed in the sawdust.

Upon repetition of Nĕmec's experiments I found that a considerable number of the roots behaved as he reported. ${ }^{3}$ In my experiments roots of Vicia faba var. major and var. equina and of Lupinus albus and Pisum satiøum were employed. As in Nĕmec's experiments, the roots frequently behaved in the same manner when they were inverted in loose moist sawdust at the very beginning of the experiment instead of being permitted to undergo curvature from the inverted position in air. After thirty-six hours these roots had so curved that the elongating zone was nearly horizontal and the curved tips pointed obliquely downward. When the cultures were then placed so that the root tips pointed directly downward, there followed in a varying proportion of the individuals an upward curvature of the tip which was always opposite to the original tip curvature. This upward curvature, which was in some cases very acute, was never completely fixed but was always somewhat flattened as the root grew. The curved region was also pushed forward from behind by the elongation of the region of the root behind it. Thus thirty-six to forty-eight hours after the upward curvature took place the root exhibited a flat curvature some distance below the position which the tip of the root had occupied. In earth the upward curvature was almost entirely suppressed and when it did appear it was only as a slight and transitory upward inclination of the tip. In the experiments with roots in earth the inverted root was kept in moist air until the elongating region had reached the horizontal and the tip pointed obliquely downward.

The roots in loose sawdust which bent upward did not, in my experiments, continue to grow in the oblique direction which they reached by reason of this upward curvature. Instead, in the course

3 A full account of the conditions and course of Nemec's experiments, which mine followed exactly in method, will be found in his paper already cited. 
of subsequent elongation, they bent gradually downward until they reached the perpendicular. In this respect their behavior was like that of roots which had been allowed to grow for from thirty-six to forty-eight hours in air and which after attaining the oblique position of the elongating zone and curvature of the tip which I have described were transferred to loose sawdust without change in position. Although the rate of downward curvature varied with different individuals the final result was always the same, the attainment of a vertical position by the growing region of the root.

The striking behavior just described does not constitute conclusive evidence that the roots have become plagiotropic. In Němec's experiments and my own the apparently plagiotropic reactions were obtained even in the case of roots which had remained in loose moist sawdust throughout the experiments and yet eventually roots inverted in moist loose sawdust do reach the normal perpendicular position. There are other reasonable explanations for the upward curvature of roots which we have described than the assumption of a transitory plagiotropism by the root. As Nemmec (r904, S. 49-50) himself reported, roots with a distinct tip curvature, when rotated upon the clinostat often exhibit oscillating curvatures suggesting somewhat those which Baranetzky (I9OI) observed in the case of shoots. It may be that roots with sharply curved tips when released from onesided stimulus by having the tips directed straight downward have the same tendency to oscillate as do the roots upon the clinostat. The first of these oscillations, if more intense that the succeeding ones might be partially fixed when the root was surrounded by sawdust. Later oscillations if considerably less intense than the first might be almost completely suppressed owing to the resistance offered by the medium. If this were the case no permanent upward curvature would result in the case of roots in air, a condition borne out by the experiments which I have reported above, and the slight tendency of roots in earth to execute the upward curvature would find its explanation in an almost complete suppression of even the first oscillation. ${ }^{4}$

Whether or not the preceding explanation is correct, it is possible to determine whether the upward curvature is a plagiogeotropic reaction by transferring roots after they have been inverted in air and

4 As I shall point out later, the primary geotropic curvature of roots in soil is often suppressed by the resistance of the soil until some time after the reaction of roots in air has begun. 
have so curved that the elongating region is horizontal and the tip directed obliquely downward to loose moist sawdust in a receptacle mounted upon a clinostat. If the "upward" curvature appears also in the case of roots rotated upon the clinostat, we must assume that the curvature is of autotropic nature rather than, as Němec believed, the result of induced plagiotropism. I have performed a number of experiments with the object of thus determining the nature of the upward bending. In each of these experiments one series of roots was treated just as were those in Němec's experiments, $i$. $e$., after inversion in air and curvature there such as has already been described, the roots were placed with the tips directed downward in loose moist sawdust, while a second series was similarly treated except that after being placed in the loose sawdust they were rotated upon the clinostat. In one of these experiments seedlings of Lupinus albus were used which, at the time they were inverted in air had lengths of from 2 to $2.5 \mathrm{~cm}$. They remained in air for 36 hours. The roots were then divided into two series, one of which was placed upon the clinostat while the other remained stationary with the root tips directed downward. Of fourteen roots on the clinostat, nine showed a distinct "upward" curvature while five merely flattened the curvature of the tip and then elongated in a straight line. The same number of the fourteen control roots as of the clinostat roots curved "upward." A similar experiment, in which roots of Pisum sativum were employed, gave corresponding results. Of twelve of these roots rotated upon the clinostat, seven flattened the original curvature of the tip and bent "upward." Of eleven control roots, similarly treated, save that they remained at rest, four exhibited the upward curvature and all subsequently bent downward into the perpendicular. Other experiments with Pisum sativum and Vicia faba gave similar results.

Since the curvatures which Nermec considered the result of induced plagiotropism also take place upon the clinostat, they must be considered as autotropic. Not only is there no permanent taking on of plagiotropism by the root in air but the upward curvatures are not even the result of a transitory plagiotropism.

Particularly significant in this connection is the behavior of roots planted horizontally or obliquely upward or inverted in loose moist sawdust behind the glass plate of a Sachs's box. These roots bend downward in a curve of very large radius as is shown by the accompanying figure which is traced directly from photographs. 
The radius of curvature in the case of root " $\mathrm{B}$ " was $64 \mathrm{~cm}$. For more than forty hours the elongating zone of this root occupied positions from the horizontal to $35^{\circ}$ below the horizontal and during this time the extreme tip was directed obliquely downward. In spite of the root tip, as well as the elongating zone, being for so long a time in an extra-perpendicular position, a condition presumably favorable to the induction of the supposed plagiotropic condition, the root, by

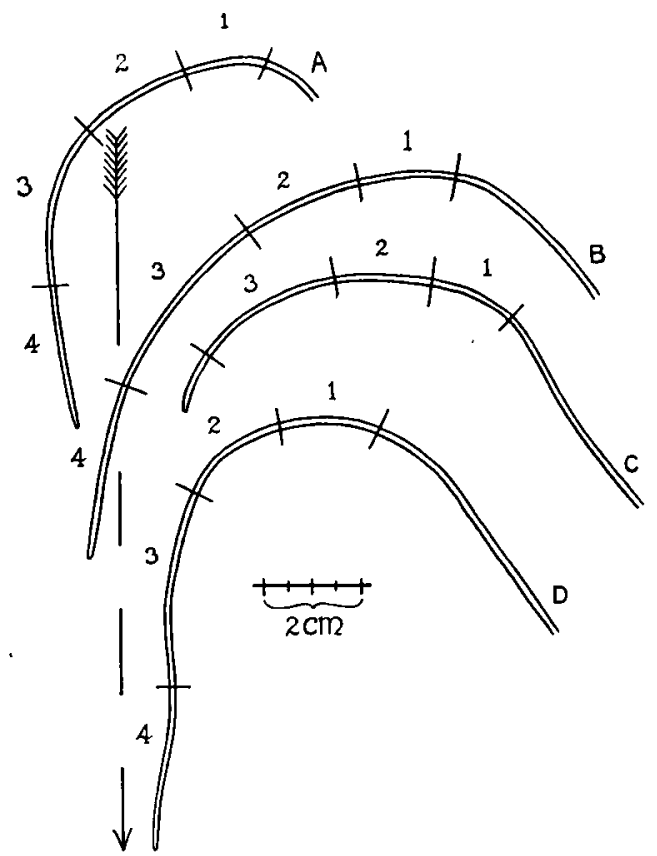

FIG. 3. Tracings from photographs of roots of Vicia faba placed obliquely upward in moist loose sawdust in a Sachs's box. The first cross stroke from the right shows the position of the tip at the beginning of the observations. The other strokes show the positions of the tip after the following intervals: $1-24$ hours, $2-24$ hours, $3-32$ hours, $4-24$ hours.

a uniform curvature, attained a position only 5 degrees from the perpendicular in the subsequent forty-six hours. In the case of another root of the same series of four (see figure $3, C$ ) after forty-eight hours growth amounting to $5 \mathrm{~cm}$., the elongating region reached the horizontal. Nevertheless in the subsequent forty-eight hours the elon- 
gating region reached the perpendicular by a uniform curvature of the root. Roots treated as above but grown at temperatures between $6^{\circ}$ and $9^{\circ} \mathrm{C}$. of ten execute so flat a curvature that the horizontal is not reached by the elongating zone for from 8 to Io days. During this time, in the case of Vicia faba and Lupinus albus the root may elongate as much as $6 \mathrm{~cm}$. Yet there is no evidence of a plagiotropic condition, for the roots always attain the perpendicular eventually.

Do roots which have undergone geotropic curvature in air lose their geotropic sensibility?

It has already been shown that roots which have grown in an extraperpendicular position in air for a considerable time curve clear to the perpendicular when brought into earth or even less compact media such as loose moist sawdust. It might be supposed that roots which have performed a geotropic curvature in air lose their sensibility to geotropic stimulus. Sachs, in fact, made this suggestion ( $1874, \mathrm{pp}$. 455-456). It is easy to show that such roots are still capable of a geotropic reaction even while growing in air. If a root which has elongated for some time in an oblique direction is displaced until the elongating region is horizontal or inclined upward an active downward curvature takes place, provided only that the root is still actively growing. Of a large number of roots in air which I have tested I have found none in which it was not possible to call forth a distinct geotropic reaction as long as active growth continued.

Do roots diverted from their normal position in earth undergo a reinforcement of their geotropic curvature?

There is no necessity for assuming an agency reinforcing the geotropic curvature of roots in soil in order to explain the oblique position in air and the perpendicular position in soil of roots which have grown twenty to thirty hours in these media after having been placed in a horizontal position. The fact that the root in soil is not free to flatten its primary geotropic curvature is sufficient to explain why the root in soil does not take up an oblique position as does the root in air. It is true that roots growing in air do not generally reach the vertical as the result of the primary geotropic curvature but the incomplete primary curvature of such roots is probably due to interruption of the curvature by the autotropic counter reaction (cf. Simon, I9I2, Table X).

But on the other hand the prompt curvature into the perpendicular when placed in soil of roots which have grown in the oblique position 
in air for several days without showing any secondary curvature does indicate that in the soil some agency is operative which assists the root in its secondary geotropic reaction. Thus if a root which has grown for some time in the oblique position in air is placed in the horizontal it bends downward until the oblique position is again attained. If it is placed horizontally in earth, on the other hand, the secondary reaction does not cease when the oblique position is reached but continues until the elongating zone is in the perpendicular. That this influence of the medium is not dependent upon the material but rather upon its physical properties is indicated by the fact that roots in air and in water behave alike in this respect and those in earth, moist compact sawdust and compressed sphagnum alike curve cleat to the perpendicular. In the case of moist sawdust or sphagnum the acuteness of the secondary curvature can be widely varied by compacting the medium to different degrees. When the medium is firmly compressed the curvature of the roots growing in it is as prompt as when soil is employed as a medium. When the sawdust or sphagnum is rendered as loose as possible the downward curvature may be scarcely perceptible even after twenty-four to thirty-six hours. Reference to figure 4 will make clear the difference in the secondary curvature in air and in loose and compact sawdust. The behavior of the root in compact sawdust (represented at $C$ in figure 4 ) differs in no respect from that of roots in earth.

What is the agency which reinforces the curvature of roots in earth and other firm media? .

In this section it is my object to consider what reinforcing agency it is which is responsible for the greater acuteness of the secondary curvature of roots growing in earth, sand, compacted sawdust, or compressed sphagnum than in air and in loose sawdust or sphagnum. The media such as moist sawdust or sphagnum the degree of compactness of which can be greatly varied will possess in varying degree, according to the extent to which they are compressed, the following properties which can be conceived of as reinforcing the root curvature: first, moisture content, the amount of water in unit volume of the medium would be increased by compression; second, content of dissolved substance in unit volume of the medium, this would likewise be increased by compression; third, permeability to gases, the rate of gas interchange would become lower as the medium was rendered more compact; and fourth, the resistance offered to the passage of a 
body through the medium, which would increase as the compactness of the medium was increased. I shall consider in turn the possibility of each of these properties contributing to the difference in the secondary curvature in loose and in compacted sawdust or sphagnum and

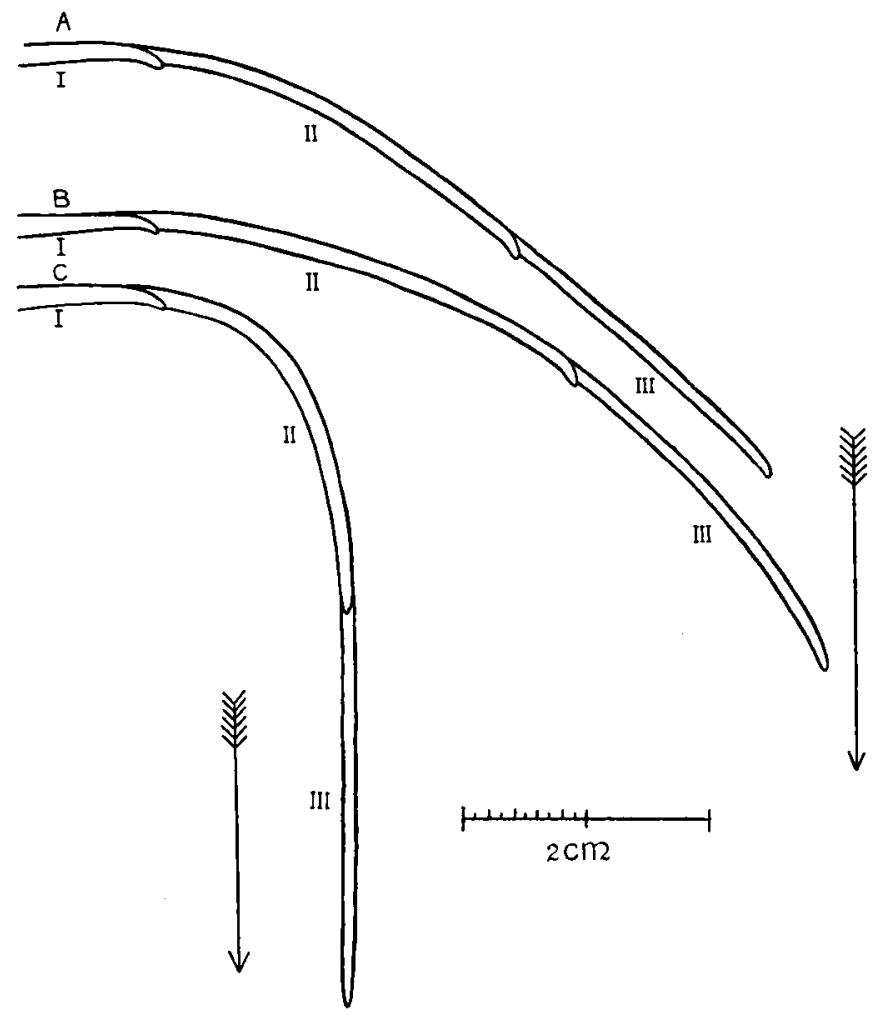

FIG. 4. Curvature of three roots of Vicia faba placed horizontally in air $(A)$, loose moist sawdust $(B)$, and firmly compressed moist sawdust $(C)$ after the roots had first curved downward in air and flattened the curvature.

to the difference in the curvatures taking place in air and in earth. Except when the roots in air are almost constantly sprayed, they are less abundantly supplied with water than when growing in moist soil. Moreover gas interchange is free in the case of roots in air and no appreciable resistance is offered to the advance of the root tip.

Clearly the amount of water at the disposal of the roots is greater 
when they are growing in sawdust or sphagnum which is compressed than when they are surrounded by these media in a very loose condition, provided, of course, that, as in my experiments, the proportion, by weight, of water to the medium is in both cases the same. As previously mentioned in connection with the discussion of Hofmeister's theory, any attempt to explain the differences in behavior of the roots in different media as due to differences in water content appears to be finally contradicted by the fact that roots in water behave very much as do those in moist air. It is conceivable however that neither the condition of water shortage prevailing in moist air nor the relatively limited gas interchange in the case of roots submerged in water is favorable to an acute permanent curvature. In this connection I performed experiments with roots which were permitted to curve in response to gravity while growing in earth containing water in different proportions. For this purpose sieved garden earth was employed which was dried in thin layers for four days at $50^{\circ} \mathrm{C}$., after which it had lost 28 percent of its weight. Roots planted in this dried soil soon died. The soil was then divided into three lots and water was added to these in the proportions of 20 percent, approximately 30 percent and 40 percent of the dry weight. Six of the eighteen roots of Vicia faba var. equina used, were planted in each of these three lots of earth in Sachs's boxes. All of the roots curved promptly into the perpendicular. The mean rate of downward curvature was, as is shown by the measurements in Table VI, nearly the same for all three cultures.

In the case of these cultures and those of other similar experiments which I have performed, the curvatures in two lots of earth of which one contained twice as much water as the other (in this case 20 percent and 40 percent of the air dry weight) showed no difference in intensity. In cultures in loose moist sawdust and in moist sawdust so compressed that a given volume contains twice the amount of water in the same volume of the loose sawdust, the curvatures are of entirely different form.

It seems certain that, although differences in the amount of moisture in the medium may not be without influence upon the geotropic curvature, this factor cannot explain the great difference in the secondary curvature of roots in air or very loose sawdust and in earth or compressed sawdust. Furthermore roots in air, even when they are so frequently sprayed that they are constantly covered with a 
film of water, show no tendency to the acute and complete secondary curvature characteristic of roots in compact non-fluid media.

TABLE VI

Roots of Vicia faba var. equina Performing Geotropic Curvatures in Soils Containing Different Percentages of Water

\begin{tabular}{|c|c|c|c|c|c|c|c|c|}
\hline \multirow[b]{2}{*}{$\begin{array}{c}\text { Percentage of } \\
\text { Water to Air Dry } \\
\text { Soil }\end{array}$} & \multicolumn{4}{|c|}{ Original Position Horizontal } & \multicolumn{4}{|c|}{ Original Position Obliquely Upward $\left(150^{\circ}\right)$} \\
\hline & $\begin{array}{c}\text { Root } \\
\text { Number }\end{array}$ & $\begin{array}{l}\text { Angle } \\
\text { After } \\
\text { ICm. } \\
\text { Growth }\end{array}$ & $\begin{array}{l}\text { Angle } \\
\text { After } \\
2 \text { Cm. } \\
\text { Growth }\end{array}$ & $\begin{array}{c}\text { Minimum } \\
\text { Radius } \\
\text { of Curva- } \\
\text { ture }\end{array}$ & $\begin{array}{c}\text { Root } \\
\text { Number }\end{array}$ & $\begin{array}{l}\text { Angle } \\
\text { After } \\
\text { Cm. } \\
\text { Growth }\end{array}$ & $\begin{array}{l}\text { Angle } \\
\text { After } \\
2 \mathrm{Cm} \\
\text { Growth }\end{array}$ & $\begin{array}{c}\text { Minimum } \\
\text { Radius } \\
\text { of Curva- } \\
\text { ture }\end{array}$ \\
\hline $20 \%$ & $\begin{array}{l}\text { I } \\
2 \\
3 \\
4\end{array}$ & $\begin{array}{l}64^{\circ} \\
37^{\circ} \\
14^{\circ} \\
65^{\circ}\end{array}$ & $\begin{array}{l}29^{\circ} \\
17^{\circ} \\
14^{\circ} \\
50^{\circ}\end{array}$ & $\begin{array}{ll}\text { Io } & \mathrm{mm} \\
\text { I0 } & \text { “ } \\
\text { I } & \text { “ } \\
20 & \text { " }\end{array}$ & $\begin{array}{l}\text { I } \\
\mathbf{2}\end{array}$ & $\begin{array}{l}82^{\circ} \\
16^{\circ}\end{array}$ & $\begin{array}{r}38^{\circ} \\
9^{\circ}\end{array}$ & ${ }_{8}{ }_{8} \mathrm{~mm}$ \\
\hline $28 \%$ & $\begin{array}{l}\text { I } \\
2 \\
3 \\
4\end{array}$ & $\begin{array}{l}27^{\circ} \\
5^{\circ} \\
51^{\circ} \\
35^{\circ}\end{array}$ & $\begin{array}{l}27^{\circ} \\
29^{\circ} \\
30^{\circ} \\
15^{\circ}\end{array}$ & $\mid \begin{array}{ll}8 & ، \\
17.5 & ، \\
20 & ، \\
17.5 & ،\end{array}$ & $\begin{array}{l}\text { I } \\
2\end{array}$ & $77^{\circ}$ & $35^{\circ}$ & $\begin{array}{rr}13 & 1 \\
9 & 1\end{array}$ \\
\hline $40 \%$ & $\begin{array}{l}\text { I } \\
2 \\
3 \\
4\end{array}$ & $\begin{array}{l}32^{\circ} \\
36^{\circ} \\
41^{\circ} \\
36^{\circ}\end{array}$ & $\begin{array}{l}21^{\circ} \\
23^{\circ} \\
18^{\circ} \\
20^{\circ}\end{array}$ & $\mid \begin{array}{ll}16 & ، \\
18 & ، \\
17 & ، \\
10 & ،\end{array}$ & $\begin{array}{l}\text { I } \\
2\end{array}$ & $\begin{array}{l}68^{\circ} \\
89^{\circ}\end{array}$ & $37^{\circ}$ & $\begin{array}{l}\text { I3 } \\
\text { 10 }\end{array}$ \\
\hline $20 \%$ & Mean & $45^{\circ}$ & $27.5^{\circ}$ & I 3 & Mean & $49^{\circ}$ & $23.5^{\circ}$ & II.5 “ \\
\hline $28 \%$ & Mean & $41^{\circ}$ & $25^{\circ}$ & 16 & Mean & $74^{\circ}$ & $30^{\circ}$ & II \\
\hline $40 \%$ & Mean & $36^{\circ}$ & $20.5^{\circ}$ & I5 & Mean & $77.5^{\circ}$ & $30^{\circ}$ & |11.5 “ \\
\hline
\end{tabular}

The flat form of the curvature in air and in loose sawdust or sphagnum and the increasing acuteness of the curvature as the latter medium is compressed might, if our observations extended no further, lead us to suspect the presence of some substance having a specific action upon the root by which the sensibility to the geotropic stimulus or the ability to react could be increased. The fact that media of such widely different nature as sphagnum, moor turf and even horn meal influence the curvature of the root as does moist sawdust speaks conclusively against that possibility. Sawdust which has been repeatedly washed with water is not altered in its effect upon the curvature of the root.

In a less compact mass of such a material as moist sawdust or sphagnum, the gas exchange would be more active than when the medium was compressed. In the more compact mass of the medium 
there would be a greater tendency for carbon dioxide to accumulate and for oxygen to become depleted. The evidence in the literature in regard to the effect of increase of carbon dioxide and decrease of oxygen upon the geotropic reaction of roots (see Pfeffer, 1906, pp. I40, I 43 and I45) would lead us to expect a flatter curvature in a more compact than in a less compact medium, if indeed the accumulation of $\mathrm{CO}_{2}$ and depletion of $\mathrm{O}_{2}$ reached a degree sufficient to affect the geotropic reaction at all under these circumstances. In water on account of the relative high solubility of $\mathrm{CO}_{2}$ as well as on account of the hindrance which the walls of the containing vessel would offer to diffusion the effect of the accumulation of $\mathrm{O}_{2}$ and accumulation of $\mathrm{CO}_{2}$ would in all probability be more extensive than in earth. Yet, in water, the root behaves very much as in air.

\section{TABLE VII}

Measurements of the Resistance Offered by Soil and Loose Moist Sawdust to Penetration by a Glass Rod Having the Form of a Primary Root of Vicia faba var. equina

Medium

Loose moist sawdust 6 days after being placed in a

Sachs's box................. I7 grams

\begin{tabular}{|c|c|c|}
\hline 17 & “ & \\
\hline I5 & “" & $16+4=20$ \\
\hline I 7 & " & \\
\hline 16 & “ & \\
\hline 7 & “ & \\
\hline 8 & “ & $7+4=I I$ \\
\hline 7 & “" & \\
\hline
\end{tabular}

Moist sieved garden soil 6 days after being placed in a Sachs's box

$$
\begin{array}{lll}
80 & \text { “ } \\
80 & \text { “ } \\
85 & \text { “ } & \\
95 & \text { “ } & \\
89 & \text { “ } &
\end{array}
$$

With compression, the resistance offered to the advance of the root tip in such media as sawdust or sphagnum would vary greatly and in earth it would be relatively high. In air or water, on the other hand, it would be entirely negligible. By means of a glass rod whose extremity was given the approximate form of the root tip of Vicia 
faba var. equina, I made measurements of the relative resistance offered to the advance of the root tip through certain of the media which I employed. The root model was of one fourth greater diameter than the root after which it was made. The rod was first forced into the medium for one centimeter of its length. Then weights were placed upon a pan fixed to the upper end of the rod until the rod had penetrated a given distance into the material. The determinations given in Table VII are typical of those obtained in all the experiments.

This very considerable difference in the penetrability of the media may be conceived of as influencing the form of the downward curvature in one of two ways; indirectly by making possible contact stimuli of different intensities or directly by mechanically assisting in the geotropic reaction in some such way as I have already suggested. (See p. 282 of this paper.)

It is possible to explain the differences in the rate of secondary curvature of roots in loose sawdust or sphagnum and in these media when compressed or in soil if we accept Sachs's and Němec's assumption that roots of the species which we and they have employed are positively thigmotropic. The more compact the medium the more resistance it would offer to the change in the form of the root which results from the geotropic reaction. The more resistance the medium offered the more intense would be the thigmotropic stimulus and the more intense the reaction. Thus the downward curvature, the sum of thigmotropic and geotropic reactions, would become more and more acute the greater the compactness of the medium. It would not, however, be so easy to explain in this manner the fact, already referred to, that roots which have been growing obliquely downward in air for several days without appreciable curvature promptly bend downward when placed in soil or other compact media. In this case we are at a loss to account for the initial downward curvature which must occur before the root receives that one-sided contact stimulus which Sachs's theory demands. Moreover the evidence for the thigmotropism of terrestrial roots of the species which Sachs, Němec and I myself have used is indeed meager. The curvatures which Darwin (I88o, p. 528 ff.) reported to be negative reactions to contact stimuli were shown by Detlefsen (1882, S. 627) and others to have been in all probability traumatropic curvatures. The positive thigmotropism of terrestrial roots, which here concerns us, was first asserted by Sachs (I874, S. 437, 438). He experimented with roots of Pisum, Phaseolus, 
Vicia faba and Zea. The roots were placed horizontally in air with a pin or piece of wood in contact with one side of the root at a point about $\frac{1}{2} \mathrm{~mm}$. behind the extremity of the cap. Positive curvatures were observed in the case of some roots. The concave side of these curvatures were toward the pin or piece of wood and the part of the root which had grown past the object lost the curvature. The curvature became permanent only when the part of the root behind the object had discontinued growth, the permanent curvature being at the point of contact with the "stimulating" object. Newcombe (I902, $b, \mathrm{~S} .243 \mathrm{ff}$.) by a large number of experiments carried out with great care, has demonstrated that when all possibility of injury to the root by the "stimulating" object is excluded, the roots of the species which Sachs employed exhibit no thigmotropic reaction whatever. He looks upon Sachs's curvatures as traumatic in nature, resulting from direct injury to the tissue and consequent lessened rate of growth at the point of contact.

Nĕmec (I90I, $a, \mathrm{~S} .87$ ) reported, as evidence of positive thigmotropism in the case of roots of Vicia faba, positive curvatures, resulting from placing on one side of the root tips droplets of plaster of Paris and water. Newcombe repeated these experiments (I904, S. 6I, ff.) without obtaining any curvatures whatever. He employed only nine individuals and grants on that account that his negative results were no sufficient contradiction of Nermec's assertion. However, as Newcombe has pointed out, it is exceedingly difficult to determine whether such curvatures as Nermec reported are thigmotropic, chemotropic, hydrotropic or simply the result of prevention of growth of the tissue to which the dried drop of plaster is attached.

I have not thought it necessary to repeat Newcombe's painstaking experiments but have endeavored to supplement them by determining whether a horizontally placed root which had previously grown for some time in an oblique position in air could be induced by contact "stimulation" to bend clear to the perpendicular in air. I used cylinders of different materials to furnish the contact "stimulus." These were in each experiment of such a diameter that the curvature of the surface corresponding to the secondary curvature of the roots when they were removed from the oblique position in which they had been growing in air and were placed horizontal without contact. Thus when the roots were placed horizontal and in contact with the cylinders in air the curvature of the root kept the under side in contact 
with the cylinder. The cylinders were of three different sorts: glass tubes both smooth and ground, plaster of Paris cylinders well washed in water, and paraffine cylinders the surfaces of which were roughened by rolling in fine sand. Vicia sativa and Vicia faba seedlings were employed and proper precautions were taken to prevent hydrotropic reactions, the roots being frequently sprayed and the air around the roots being kept very moist throughout the experiments. The results were entirely negative. The roots in most cases remained in contact with the cylinders until the elongating regions of the roots were inclined from $30^{\circ}$ to $60^{\circ}$ from the perpendicular. They then left the surface of the cylinders and grew nearly straight ahead.

Altogether it may be said that there exists no conclusive evidence that the species Sachs and Němec employed and those which I have employed are thigmotropic. We are certainly justified in assuming that thigmotropism if, as seems highly improbable, it exists in the case of terrestrial roots, is of sufficient intensity to account for the difference of secondary geotropic curvature in air and earth. Still less can it account for the great difference in the curvature in loose and in compact sawdust or sphagnum.

It remains for us to consider whether it is the direct mechanical influence of the medium upon the reaction of the root which brings about the reinforcement of the geotropic curvature. When a root about $2 \mathrm{~cm}$. long is placed in air at an angle of from $45^{\circ}$ to $50^{\circ}$ from the normal position, a slight downward curvature takes place which is almost completely flattened. (This is shown at $A$ in figure 2.) Thereafter the root elongates with curvature, if any, so slight as to be scarcely perceptible. The extreme tip, however, takes on the curvature already mentioned, which is maintained as the root elongates. This behavior of roots directed obliquely downward in air has been described earlier in this paper. If an obliquely directed root at the stage represented in figure 2, $A_{3}$ is planted in soil without changing its position relative to the perpendicular, it soon bends downward into the normal position. Now, as is clear from a glance at the figure referred to, it would be the upper side of such a root and not the lower side which would experience the greater friction against the soil particles as the curved tip is thrust forward through the earth by the increase in length of the region behind it. If such a root were thigmotropic in the sense in which Nemec and Sachs have maintained, the transfer from air, earth or other firm medium would 
be followed by an upward curvature or, if the thigmotropism of the root were weak, at least in a decrease in the intensity of the downward curvature. This is, however, contrary to the observed facts.

It seems rather to be a passive depression of the downward curved root tip due to the resistance offered to its advance by the medium which reinforces the secondary curvature. The downward bent or asymmetrical root tip which is thrust passively forward from behind by the increase in length of the elongating region cannot follow a straight course in a firm medium because of the non-symmetrical application of the considerable force opposing its advance. This is made clearer by the accompanying diagram (figure 5). The outline

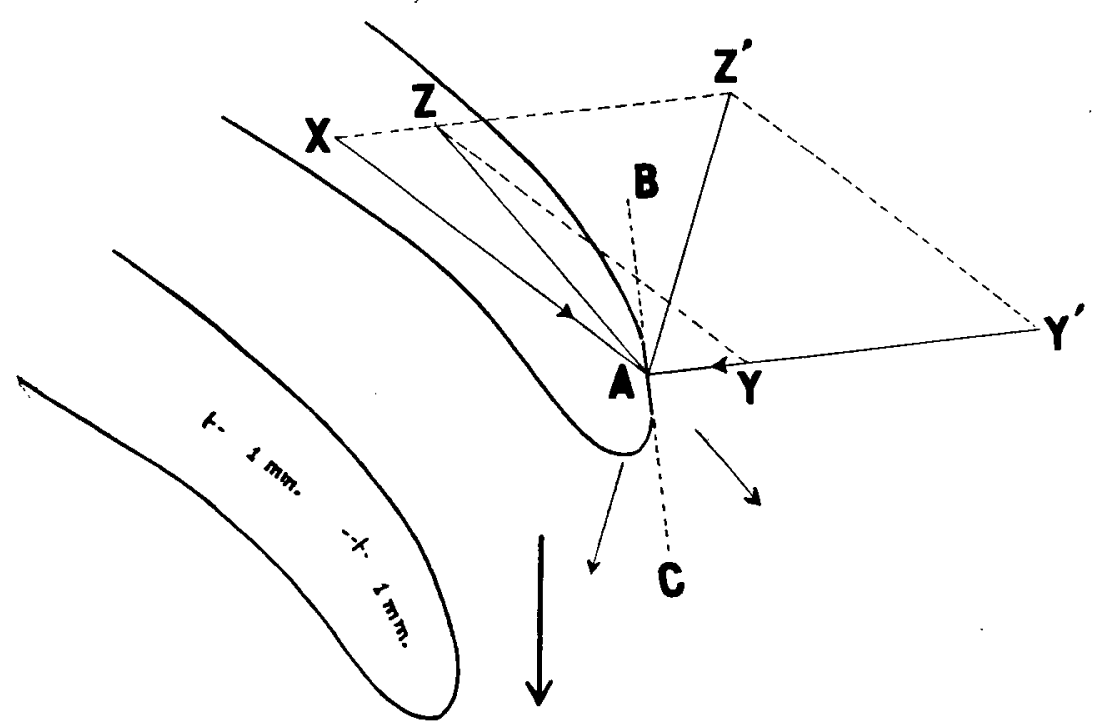

FIG. 5. Diagram illustrating the manner in which the secondary curvature of a root with"curved tip is reinforced in a firm medium. The heavy arrow indicates the perpen dicular. For further explanation see the text.

below and to the left is from a camera drawing of the tip of a root of Vicia faba and in the diagram the same outline has been used except that a portion of the upper surface has been represented as if it were a plane (the solid portion of the line $B C$.) $X A$ represents a force acting at $A$ and tending to thrust the tip forward in a direction parallel to the axis of the elongating region. This force results from the increase in length of the region of elongation. $Y A$ and $Y^{\prime} A$ represent 
respectively the resistances offered by a relatively loose and a relatively compact medium to the advance of the root tip. These forces act at right angles to the surface represented by $B C$. The resultants of the forces $X A, Y A$ and $X A, Y^{\prime} A$ are respectively $Z A$ and $Z^{\prime} A$ and their direction indicates a passive depression of the tip. There has been left out of account the friction of the root surface against the particles of the medium, a force which would act parallel to the surface. This force must be small compared with the other forces concerned. It would lessen somewhat the tendency to downward depression of the root tip but probably to only a slight extent.

This effect of the resistant medium in altering the direction of the root's growth by passive displacement of the curved tip is comparable to the effect observed when a stake sharpened to a chisel edge is driven into soil. To drive such a stake straight into hard soil is very difficult and indeed quite impossible if the driving force is applied in a direction parallel to the long axis of the stake. The behavior of the root during its secondary curvature in a firm medium can be illustrated by means of a model root, having three parts; a tip having the form of the curved root tip, an extensible portion representing the region of elongation of the root and a rigid portion, representing the part of the root in which growth has ceased. I constructed such a model in which the extensible portion was formed of small and very elastic rubber tubing. A piece of fine spring wire, which was not very stiff extended through a glass tube which formed the part of the model corresponding to the older part of the root and through the rubber tubing and was attached to the glass. "root tip." By means of this wire the "elongating region" could be increased in length and the root tip advanced. When the whole model was "planted" in earth behind the glass wall of a Sachs's box and the tip was pushed forward by means of the wire which extended through a hole in the end wall of the box the "root tip" and the adjacent portion of the "elongating region" were depressed and the "root" bent downward. Just as in the case of the living root, the greater the resistance which the medium offered the sharper was the downward curvature of the root model.

In the case of roots advancing through the soil or other compact media, the resistance of the medium tends to intensify the curvature in still another way. The tip curvature of roots growing obliquely downward, as shown in figure $2\left(A_{3}, A_{4}\right.$, and $\left.A_{5}\right)$ is constantly being 
flattened at the border of the region of active elongation and being reformed at the extremity of the tip. A non-fluid medium hinders this progressive flattening of the tip curvature to a lesser or greater extent according to the compactness of the material. The diagrams (figure 6) of successive stages in the curvature of a root in very loose sawdust,

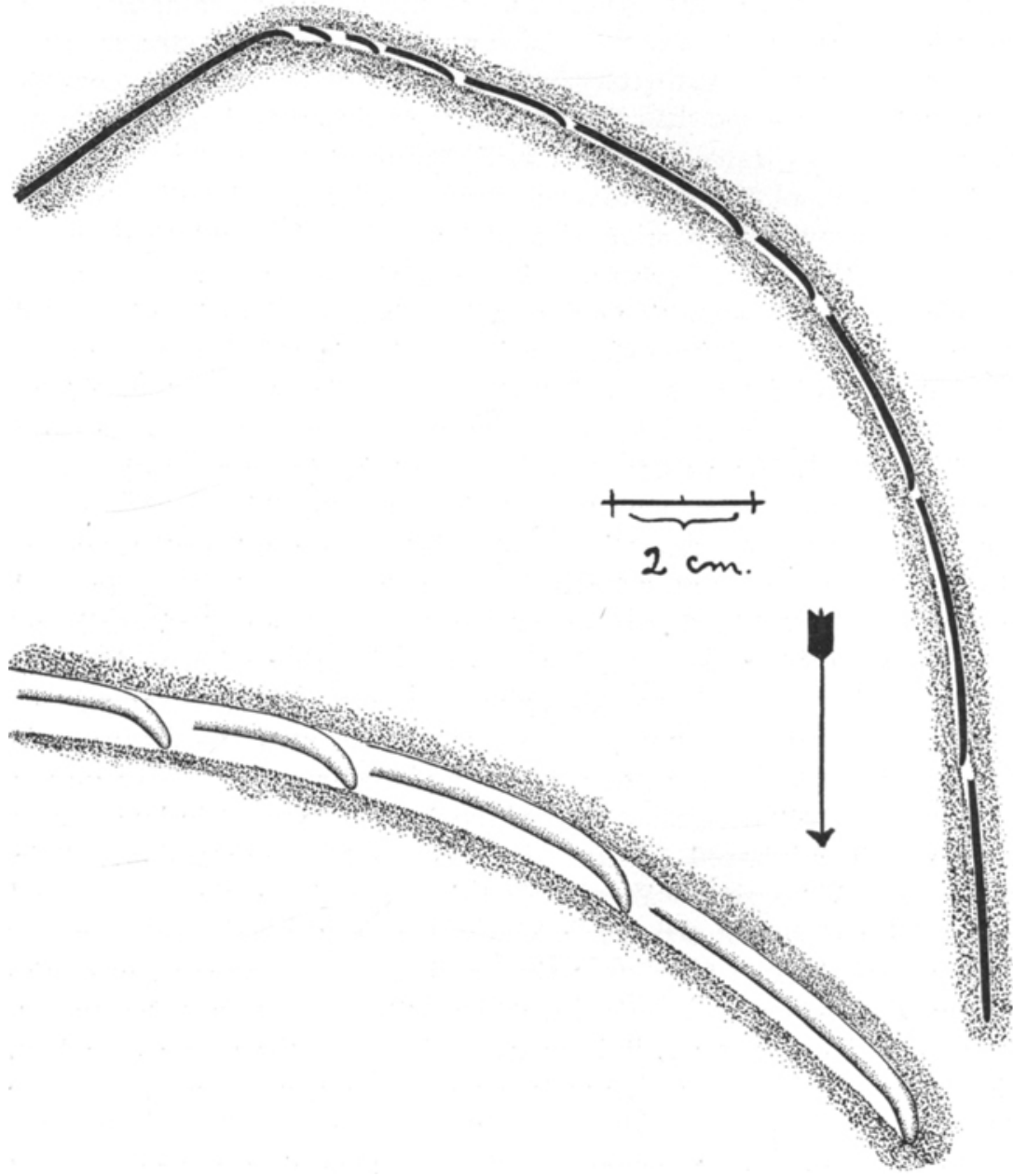

FIG. 6. The tip of a root of Vicia faba at different stages in the downward curvature of the root in loose moist sawdust. The upper drawing is from a tracing of the object itself. Below is a diagram representing the same object on a larger scale. 
illustrate this point. So little resistance was offered by the medium in the case of the root illustrated in the figure that the sawdust was pushed aside by the curved root tip and thus a channel was formed considerably wider than the root. (The more compact the sawdust the narrower this channel until in very compact sawdust the channel is not wider than the root and there is no free space below the older parts of the root such as is shown in figure 6.) Not only was the root only slightly depressed in the manner described above but also the progressive flattening of the curvature of the tip was almost complete. It is clear that in a medium which would considerably hinder or prevent the flattening of the curvature of the tip of the root the normal position would be reached more promptly and by a more acute curvature than in the case represented in the figure.

The extent of the reinforcement of the geotropic curvature due to the resistance offered by the medium depends upon two factors: the sharpness of the tip curvature and the consistency of the medium. We would expect the rate of curvature to become less as the root approaches the vertical for as the tip approaches the normal perpendicular position its curvature becomes less acute. This is frequently the case when very loose sawdust is the medium used, although the greater compactness of the medium in the lower part of the Sachs's box results in a greater resistance being offered to the advance of the root and frequently makes the difference in the rate of downward curvature inappreciable. It was not found possible to vary the resistance offered by the soil sufficiently to secure such flat secondary curvatures as those in loose moist sawdust or sphagnum except by mixing other materials with the soil. However, roots placed horizontally or inclined upward in fine, moderately moist soil so that the tip was not more than Io to $15 \mathrm{~mm}$. below the surface often curved very slowly downward during the first 2 to $3 \mathrm{~cm}$. of growth. In these cases the slight weight of soil above caused the soil about the roots to offer little resistance to the advance of the root tip. When a somewhat deeper level was reached, where, owing to the weight of the earth above, a greater resistance was offered to the root's advance, the curvature became more acute and the perpendicular position was soon attained. Sometimes, however, the curvature was so slow that the roots actually emerged from the soil and grew upward into the air.

In this section we have considered a number of points of difference 
between the media in which the secondary curvature of primary roots is acute and those in which the curvature is relatively flat or lacking, as is often the case in air after the roots have reached an oblique position. It seems to be the last of these points of difference which we have considered, that is, the varying resistance offered by the different media to the advance of the root tip, which is the only one concerned to any extent in bringing about the differences in curvature. This varying resistance does not influence the form of the curvature by making possible a thigmotropic reaction which assists the geotropic curvature. It is rather the direct mechanical effect of the medium, and probably that alone, which causes the differences in secondary geotropic curvature. In the next section experiments will be reported which had for their object the determination of the effect of the medium upon the primary geotropic curvature, that is, upon the curvature which roots which have previously grown in the normal position perform when placed in a position of one-sided geotropic stimulation.

What infuence does the medium exert upon the primary geotropic curvature of primary roots?

So striking is the difference in the secondary curvature in media offering different degrees of resistance to the advance of the root tip that the question naturally suggests itself, whether or not the primary curvature also is influenced by the resistance of the medium. The only reference which I have found relating to the course of the primary curvature in different media is the comparison made by Sachs (1874, S. 444-445) of the curvatures of roots of Vicia faba, Pisum, Phaseolus and Aesculus placed horizontally in air and earth. He stated that after 4 to 6 hours at $18^{\circ}$ to $20^{\circ} \mathrm{C}$. the roots growing in both media took on the form of an arc of a circle, the curvature involving the whole growing region. He stated further that after that time the radius of the curvature decreased, the decrease in curvature radius being most active in the region of most active elongation. Thus the curvature took on a parabolic form. After this the first difference in the form of the curvature in earth and air was observed by Sachs. He stated that in the latter medium the regions above and below the most strongly curved zone straightened somewhat so that the curvature became more localized and acute. Roots in earth, on the other hand, although somewhat more acutely bent in the elongating region than the roots in air, also showed considerable curvature above 
and below this zone. Sachs stated that the roots first showed this difference in the form of their curvatures a little time before the roots in air had reached their maximum curvature.

Now I have attempted to follow somewhat more closely than did Sachs the curvatures in air and in non-fluid media. Although it is my intention to study further the relation of the medium to the course of the primary curvature the results of my experiments have been so uniform that it is appropriate to report them in this connection. Instead of recording the course of the curvature of the roots in written notes and free-hand drawings, I made photographs of the roots at intervals during the primary curvature. The roots which grew in air were mounted on corks which were fixed in crystallizing dishes as already described (see page 278 of this paper) and throughout the course of the curvature the roots remained in the same position relative to gravity, their position not being changed while the photographs were being taken. For comparison with air, moist sawdust was used instead of earth because the penetrability of the sawdust could be readily varied and because, when soil was used as a medium, fine earth particles frequently came to lie between the root tip and the glass wall of the Sachs's box in which the roots were grown. Thus the form of the root was obscured. Repeated experiments had shown that the curvatures in earth and in moderately compressed moist sawdust were not appreciably different. Seedlings of Vicia faba var. equina and var. major were employed and photographs were made at frequent intervals of the course of the curvatures in air, in loose sawdust and in moderately compressed sawdust. While the roots were curving most actively, the intervals between exposures were shorter than when the change in the form of the roots was less active. Thus in the case of one series of photographs of roots growing at a temperature of $23^{\circ}$ to $24^{\circ} \mathrm{C}$, , the intervals between the exposures were 2 hours, I hour, $2 \frac{1}{2}$ hours, 6 hours, and 12 hours. The source of illumination employed was a $100 \mathrm{cp}$. Nernst lamp. The light passed through a glass box Io $\mathrm{cm}$. thick, which was filled with water, before falling upon the roots. The time of exposure varied from $\frac{1}{2}$ to 2 minutes according to the magnification used. The magnification was the same for all the photographs of a given series. The magnifications used in different series varied from $2 \times$ to $4 \times$. The curvatures of the roots were compared by superimposing the negatives and viewing them by transmitted light and also by mounting prints from 
the negatives upon co-ordinate paper. Marks made upon the roots by means of Chinese ink and which appeared in the photographs made it possible to so mount the prints upon the co-ordinate paper that the course of the curvatures could be easily studied and compared. No roots were used which were longer than $6 \mathrm{~cm}$. and the roots under comparison in any series were of the same length.

In the case of roots placed horizontally in air, loose sawdust and compressed sawdust, the first evidence of the beginning of the geotropic
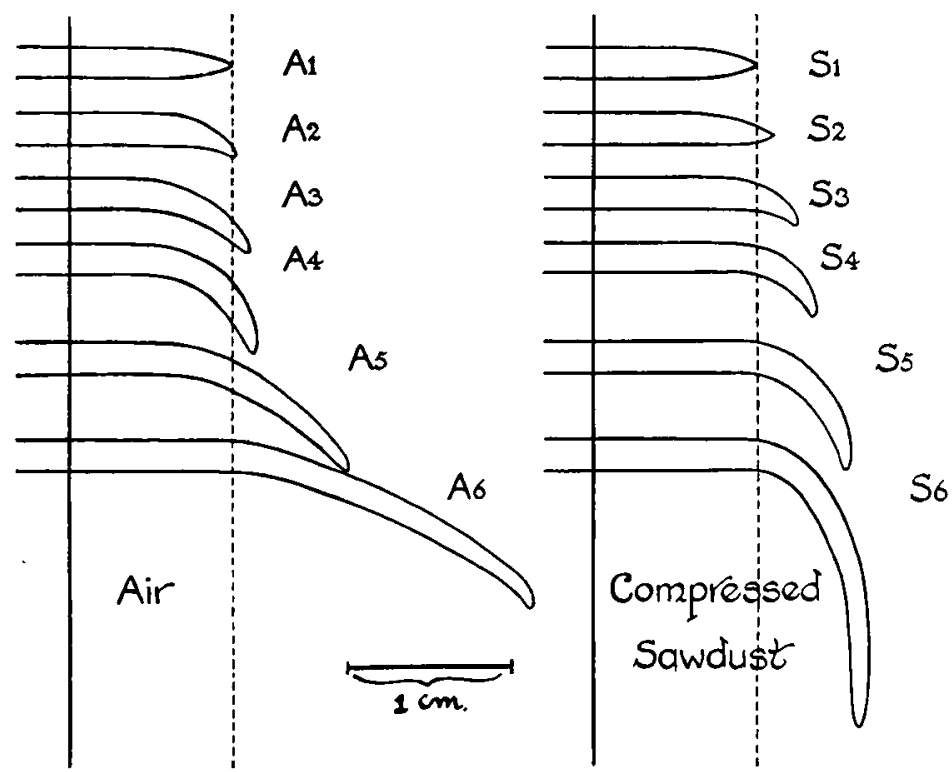

FIG. 7. Diagram showing the course of the primary curvature of main roots of Vicia faba placed horizonta! in air and in compact moist sawdust. The heary perpendicular lines cross the roots at points originally $1 \mathrm{~cm}$. from the extremity. The broken lines indicate the original nosition of the extremity of the roots. For further comment see the text.

curvature was a slight downward asymmetry of the root tip. This appeared at about the same time in the case of the roots in air and of those in loose sawdust and before the roots had undergone any appreciable elongation. Roots in compact sawdust, on the other hand, did not exhibit an asymmetry of the tip until they had undergone an appreciable elongation. (See $S_{2}$ and $A_{2}$ in figure 7.) The first ap- 
pearance of asymmetry in the case of the roots in the compact medium was generally I to 2 hours $\left(a t 20^{\circ} \mathrm{C}\right.$.) after the roots in air had shown the first trace of a reaction.

From the time of the appearance of the first trace of curvature in the case of roots in air the curvature involved more and more the region behind the extreme tip until the zone of most rapid elongation began to curve. (See $A_{3}$ in figure 7.) Meanwhile the roots in compact sawdust had curved downward somewhat. The curvature was restricted, however, almost entirely to that part of the root which was now beyond the original position (indicated in the diagram by the broken lines) of the root tip. In other words the region of the root which lay behind the original position of the tip was curved little if any. (See $S_{3}$.) The difference in the curvature of the roots in air and of those in the compressed sawdust up to this point seemed to have its cause in the relatively great resistance offered by the compact medium to any lateral displacement of the root. The terminal 4 to 5 millimeters of the roots in air were free to undergo a considerable downward displacement. (See $A_{3}$ in figure 7.) This "swinging" displacement of the part of the root beyond the region of most active elongation was in some cases so extensive that a part of the root came to lie 2.5 to $3.5 \mathrm{~mm}$. below the original position of the tip.

After the region of most rapid elongation had become involved in the curvature the bending of the roots in air continued, principally by the activity of the region of most rapid elongation, until the maximum curvature was reached. As the maximum was approached the bending became slower. In most cases the maximum curvature of the roots in air did not amount to $90^{\circ}$. Up to this point the roots in very loose sawdust behaved in a manner similar to those in air, except that the "swinging" downward displacement was hindered considerably by the resistance of the medium. It is clear that the loose sawdust much more effectively opposes the lateral displacement of 3 to $4 \mathrm{~mm}$. of the root than it does the advance of the root tip in the direction of the root's axis. As a result the maximum primary curvature of the roots in moist loose sawdust was considerably less than that of the roots in air. The roots in the compact medium bent promptly and acutely downward as soon as the terminal 2 to 3 millimeters of the roots became distinctly curved. As the curved extremity of such a root was pushed forward through the firm medium by the increase in length of the elongating region, there ensued a sharp 
curvature downward into the perpendicular, just as in the case of the secondary curvature of roots in such media which has already been discussed. Thus in spite of the fact that in the compact sawdust the beginning of visible reaction was considerable later than in moist air the roots in the former medium frequently reached the perpendicular before the roots in air had attained their maximum curvature. (See $S_{4}$ and $A_{4}$ in figure 7.) The curvature of the root in loose sawdust at the time the roots in air and the compacted sawdust had reached their maximum curvatures was less than either; less than that of the root in air because even the loose sawdust hindered the "swinging" movement resulting from the curvature of the zone of elongation and less than that of the root in compact sawdust because the resistance offered by the loose medium to the curved tip as it was thrust forward by the growth of the root was insufficient to rapidly depress the root tip.

These differences in the primary curvature of roots in the different media used are due apparently to the different degrees of resistance offered by the media to change in the form of the root and to the advance of the tip. On account of the relatively great resistance offered by the compressed sawdust to change in the form of the root, the beginning of the reaction is delayed in the case of roots in this medium. When curvature does begin it is largely restricted, as has been said, to the part of the root which has advanced beyond the original position of the tip. In air the root is quite unhampered in its reaction and the curvature begins sooner and the zone of active elongation takes a more active part in the curvature than in the compact medium. In loose sawdust the curvature is at first very slightly affected by the resistance of the medium. The root is able to displace easily the particles of the loose sawdust and at first the curvature is similar to that of roots in air. The medium lying just below the curving region is compressed by the bending of the root and the resistance offered to further bending increases until it is sufficient to prevent further active curvature of the elongating region. Subsequent curvature is rather favored than hindered by the resistance of the medium, for the extreme tip becomes acutely curved, that is, takes on the tip curvature which has been described earlier in this paper, and, being pushed forward by the elongation of the region behind it the root curves slowly downward in the manner of roots undergoing secondary curvature in the same medium. (See pages 307 and 308 of this paper.) 


\section{Conclusions}

I. That the difference in the behavior relative to gravity of roots in air and in earth is not due to differences in the amount of water in the media.

2. That the difference in behavior is not the result of change in the geotonus of the roots, due to their stay in air, whether weakening or loss of geotropism, as Sachs suggested, or assumption of plagiogeotropism as Nëmec reported.

3. That, as was shown by experiments with media the resistance of which to the root's advance could be widely varied, the failure of the roots in air to reach the vertical is due to the absence of mechanical resistance to the advance of the root tip through that medium.

4. That the secondary curvature of roots in earth, sand, sawdust, sphagnum or other such media is complete because the resistance of these media to the advance of the curved root tip causes passive depression of the root and prevents the complete flattening of the tip curvature.

5. That thigmotropism is not a factor in the difference in the behavior of roots in air and in earth or other non-fluid media.

6. That the resistance offered by the medium to movements of the root tip influences not only the course of the secondary curvature but also the course of the primary curvature, that is, the curvature directly following the placing of the root in a position of stimulation.

The preceding conclusions apply in their entirety to the three principal species employed, Vicia faba L. (var. major and var. equina), Lupinus albus L., and Pisum sativum L., although a number of forms, mostly Leguminosae, were employed in some of the experiments.

University of Michigan, ANN ARBor

\section{LITERATURE CITED}

Baranetzky. Ueber die Ursachen welche die Richtung der Aeste der Baum und Straucharten bedingen. Flora, Ergänzungsband: 138. I90r.

Berg. Studien über Rheotropismus bei den Keimwurzeln der Pflanzen. Lunds Universit. Ars-skr. $35^{2}$ : No. 6.1899.

Czapek. Ueber die Richtungsursachen der Seitenwurzeln und einiger anderer plagiotropen Pflanzentheile. Sitzungsber. Akad. Wien 104: II97. 1895.

Darwin, C. The Power of Movement in Plants. London. I880.

Detlefsen. Ueber die von Ch. Darwin behauptete Gehirnfunction der Wurzelspitze. Arb. Bot. Inst. Würzburg 2: 627 . 1882 .

Elfving. Beiträge zur Kenntnis der physiologischen Einwirkung der Schwerkraft auf die Pflanzen. Acta Soc. Fenn. 12: 32. 1880. 
Holman. A Useful Drawing Camera. Pl. World I8: II3-II6. I9I5.

Hofmeister. Ueber passive und active Abwärtskrümmung von Wurzeln. Bot. Zeit. 28: 33-35, 50-5I, 91-92. I869.

Jost. Vorlesungen über Pflanzenphysiologie. Jena. Aufl. 2. I908.

Juel. Untersuchungen über Rheotropismus der Wurzeln. Jahrb. Wiss. Bot. 34: 507. 1900.

Němec. Ueber die Wahrnehmung des Schwerkraftreizes bei den Pflanzen. Jahrb. Wiss. Bot. 36: 80. I90I (a).

Ueber das Plagiotropwerden orthotroper Wurzeln. Ber. Deutsch. Bot. Ges. 19: 310. 1901 (b).

Einiges über den Geotropismus der Wurzeln. Beih. Bot. Centralbl. I7: 45. I904.

Newcombe. The Rheotropism of Roots. Bot. Gaz. 33: 269. $1902(a)$.

Sachs's angebliche thigmotropische Kurven an Wurzeln waren traumatisch. Beih. Bot. Centralbl. I2: 243. $1902(b)$.

Thigmotropism of Terrestrial Roots. Beih. Bot. Centralbl. r7: 6r. I904.

Pfeffer. Physiology of Plants. English trans. by Ewart. Vol. 3. 1906.

Sachs. Ueber das Wachsthum der Haupt- und Nebenwurzeln. Arb. Bot. Inst. Würzburg I: 385 . I 874 .

Simon. Untersuchungen über den autotropischen Ausgleich geotropischer und mechanischer Krümmungen der Wurzeln. Jahrb. Wiss. Bot. 51: 8I-1 78 . I9I2. 